\title{
Access to electricity in the World Energy Council's global energy scenarios: An outlook for developing regions until 2030
}

\author{
Evangelos Panos*, Martin Densing ${ }^{1}$, Kathrin Volkart ${ }^{2}$ \\ Paul Scherrer Institute, Switzerland
}

A R T I C LE I NFO

Article history:

Received 19 June 2015

Received in revised form

7 November 2015

Accepted 13 November 2015

Available online 14 December 2015

\section{Keywords:}

Universal electricity access

GMM MARKAL model

Econometric modelling

World Energy Council

Global energy system modelling

\begin{abstract}
A B S T R A C T
Approximately 2 out of 10 people in the world still live without access to electricity. The UN "Sustainable Energy to All - SE4All" initiative aims at eradicating this electricity access deficit by 2030 . To estimate the financial effort required to achieve this target we analyse two long-term scenarios developed by the Paul Scherrer Institute and the World Energy Council, which describe two alternative economic and energy system developments. We focus on developing Asia, Latin America and Sub-Saharan Africa, which currently have the largest percentage of population without access to electricity. We couple a long-term energy system model with regional econometric models that forecast population electrification rates. We find that establishing universal electricity access by 2030 requires significant, but attainable investments in power generation infrastructure, and results in low impacts on primary energy demand and $\mathrm{CO}_{2}$ emissions.
\end{abstract}

(c) 2015 Elsevier Ltd. All rights reserved.

\section{Introduction}

Access to electricity is essential to overcome poverty, promote economic growth and employment opportunities and support the provision of social services such as education and healthcare that lead to sustainable human development [1]. The International Energy Agency (IEA) defines electricity access as a first supply connection to a household and then an increasing level of electricity consumption to reach the regional average. This approach reflects the fact that the eradication of energy poverty is a long-term endeavour [2]. Following the IEA definition 1267 million people worldwide did not have access to electricity in 2010 [3]. This figure increased to 1285 million in 2012 [4], implying that population growth outpaced the number of new electricity connections. More than $95 \%$ of the population without access to electricity lives in developing Sub-Saharan Africa, Asia and Latin America (Fig. 1).

\footnotetext{
* Corresponding author.

E-mail addresses: evangelos.panos@psi.ch (E. Panos), martin.densing@psi.ch (M. Densing), kathrin.volkart@psi.ch (K. Volkart).

1 Tel.: +41563102598.

2 Tel.: +41563105779 .
}

In September 2011, UN Secretary-General Ban Ki-Moon launched the initiative "Sustainable Energy for All - SE4All" to mobilise action from all sectors of society to promote universal electricity access by 2030 [5]. The initiative has generated significant momentum and more than 100 countries are already participating in it. As global development agendas are increasingly recognising energy access and energy poverty as essential issues for society, it is important to address them in the context of two other significant socio-ecological issues of our time: energy security and environmental sustainability [6]. This triple challenge is referred by the World Energy Council (WEC) as the "energy trilemma" [7].

The Paul Scherrer Institute (PSI) together with WEC developed two energy scenarios to 2050 assessing the energy trilemma at global and regional scales [8]. The two scenarios incorporate a coherent set of key economic, social and political drivers that are quantified and implemented with a detailed energy system model. The WEC/PSI scenarios are exploratory in their nature in the sense that no specific targets were set along the axes of the energy trilemma. The first scenario ("Jazz") is market-facilitated with a focus on achieving economic growth through competitive and low-cost energy. The second scenario ("Symphony") considers stronger policy regulations with priority given to environmental sustainability and energy security. Both scenarios include climate policies and recent technological advances. 


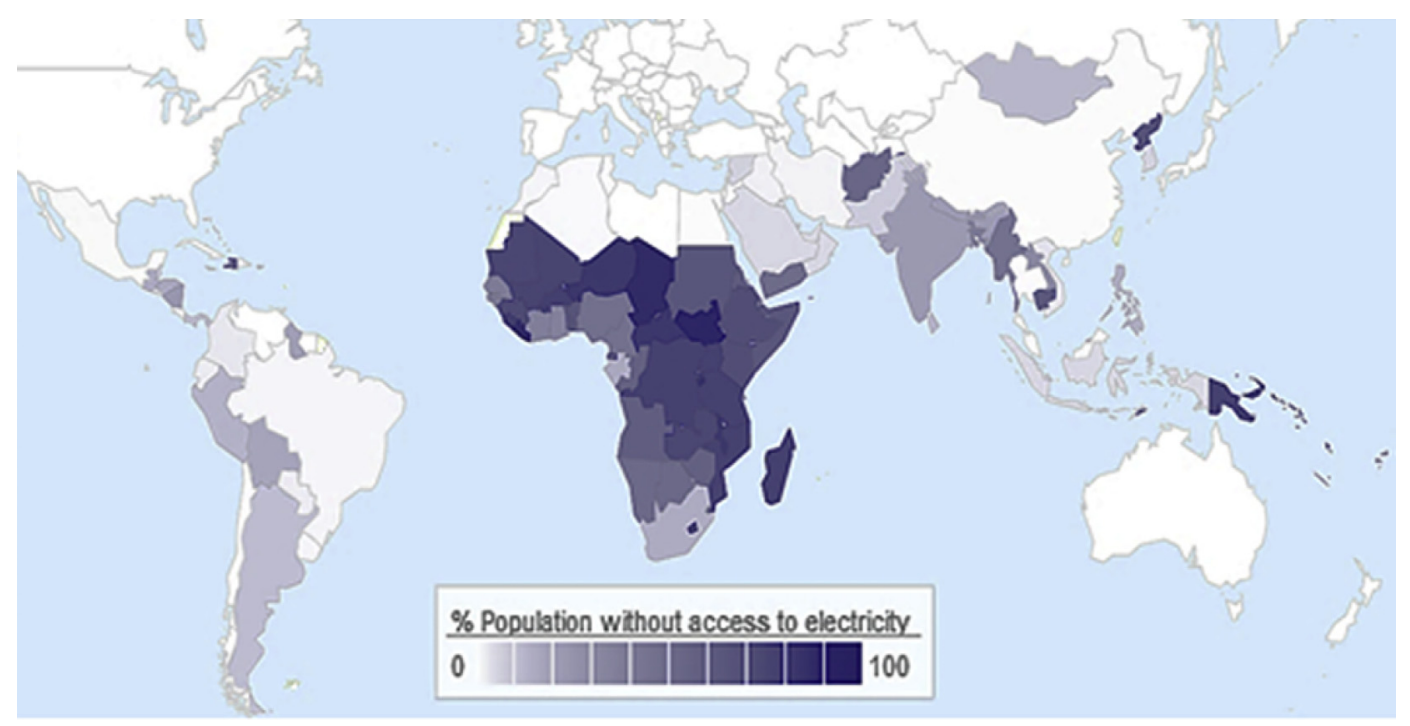

Fig. 1. Population without access to electricity as \% of country's population, 2010 (source: own illustration using data from Ref. [3]).

In this paper, we present a detailed analysis of the two WEC/PSI scenarios regarding electricity access in developing and emerging regions. We focus on regions in which a significant share of the population lacks access to electricity: Sub-Saharan Africa, developing Latin America, India, Central Asia, developing Pacific Asia, Middle East and North Africa. ${ }^{3}$ For each region, we present the outlook of electricity access in WEC/PSI scenarios until 2030, we discuss the key socioeconomic drivers affecting it and we evaluate the additional investment effort in power generation infrastructure required to achieve universal electricity access by 2030. In our assessment, we use an analytical approach, in which we couple a large scale bottom-up energy system model that identifies long term cost-optimal configurations of the energy system with regional reduced-form econometric models ${ }^{4}$ that forecast the population with access to electricity.

\subsection{Literature review}

In general, the majority of research on improving electrification in developing countries, analysing its impacts on energy supply and emissions and identifying drivers and policies with significant contribution to the electricity access, can be divided into four main categories. The first category includes studies that describe current situations of energy demand or consumption and evaluate the outcomes of policy and programs in developing countries. This includes assessments of funding needs and financing mechanisms (e.g. Ref. [9]), evaluations of electrification programmes (e.g. Ref. [10]), policies and reforms required (e.g. Ref. [11]), and case studies at national and regional levels (e.g. Refs. [12-23]). The studies belonging in this category of research include legal, social and fiscal aspects of the policies and programs. However, they are usually highly case-oriented and it is difficult to obtain ideas applicable to other areas.

The second type of research category focuses on the potential of various electricity supply technologies to increase electricity access such as solar photovoltaic systems (e.g. Refs. [24,25]), decentralised generation and micro-grids (e.g. Refs. [26-30]), nuclear power [31],

\footnotetext{
${ }^{3}$ We exclude Brazil and China, since they already display high electrification rates and they are expected to achieve universal electricity access before 2030 ([3], [8]).

${ }^{4}$ An econometric model is in a reduced-form when it has been rearranged algebraically such that each endogenous variable is on the left side of the equation, and only predetermined variables (exogenous variables and lagged endogenous variables) are on the right side.
}

biomass [32], etc. This type of studies often contains highly disaggregated or highly precise data, but policy implications to promote these technologies are usually not sufficiently discussed.

The third category includes studies investigating relationships between electrification, poverty and economic development on national and regional scales. These studies can be qualitative, based on empirical results from past experiences (e.g. Refs. [33-35]), or quantitative, based on econometric analysis (e.g. Refs. [36-43]). The majority of these studies identify poverty, income, foreign direct investments (FDI), urbanisation, country policy and institutional development, electricity prices, subsidies and average electricity consumption per capita as key factors of electricity access.

Finally the fourth type of research, to which the present study belongs, involves the combined application of top-down and/or bottom-up economic and energy system models with specific microeconomic consumer choice models or econometric models. These studies forecast the population with electricity access by taking into account economic developments, technological parameters and governmental policies. At the same time, they evaluate the broader impacts of increased energy access on energy supply and demand fuel mix, investment requirements and greenhouse gases emissions. Bottom-up modelling frameworks, such as TIMES [44], have been employed in projecting rural electrification (e.g. for Africa in Refs. $[45,46]$, and for other developing regions in Ref. [47]). Top-down approaches have been used for electricity access scenarios for SubSaharan Africa [48] and for assessing the impacts of increased energy access on greenhouse gases emissions and global warming [49]. In Ref. [50], a consumer choice model based on micro-economic foundations is implemented within the cost optimisation energy system model MESSAGE [51]. The model analyses the determinants of fuel consumption choices of heterogeneous household groups by taking into account effects of income distribution, consumer preferences and discount rates. It has been applied to explore response strategies for energy poverty eradication in India [50] and in South Asia [52], and to evaluate pathways to achieve universal electricity access by 2030 [53-55].

The International Energy Agency applies an econometric model to generate projections of electrification rates by developing region. It is based on panel estimation of historical electrification rates of different countries over income, urbanisation, fuel prices and subsidies, electricity consumption, electrification programmes and other variables [56]. The model is interfaced with IEA's World Energy Model (WEM) in the World Energy Outlook series (e.g. Refs. [2-4]). 


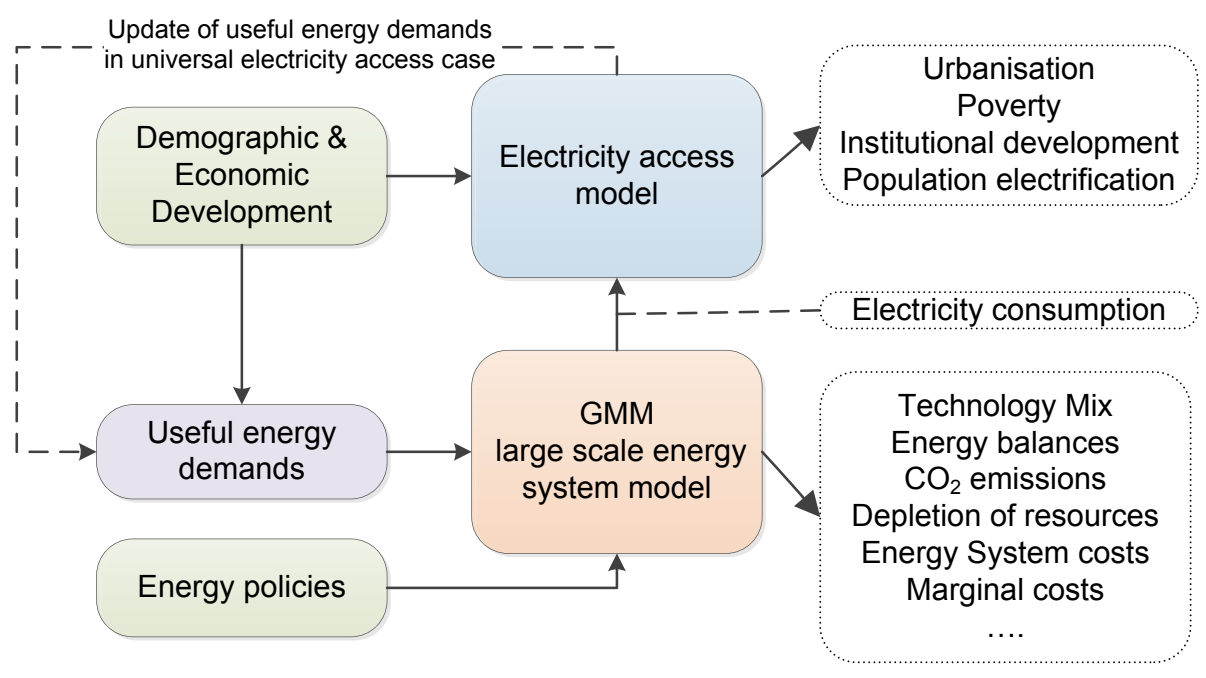

Fig. 2. Overview of the modelling framework.

In Ref. [57] a bottom-up residential energy use model was developed, which determines the fuel use in households based on relative differences in perceived costs by following a causal chain from population and income trends to intermediate physical indicators and energy uses. It makes also use of correlations derived from econometric studies and regression analysis to project household energy consumption and electrification rates in urban and rural areas. The model is integrated into the IMAGE/TIMER global energy simulation model [58], and it has been applied to determine the fuel use in households in India [57] and to evaluate universal electricity access scenarios [54].

In Refs. [59], an econometric model for projecting the rural electrification in developing countries is described. The model uses multivariate regression analysis including as statistical significant variables (among others) the electrification level, the population density, the urbanisation, the average per capita income, the exports of goods and services, the fuel exports and the foreign direct investments. The projected rural population electrification rates are then used in a simple power grid expansion model that takes into account the costs of different grid components in order to evaluate the cost of increased electricity access.

We contribute to the existing literature described above by applying a modelling framework that is based on the coupling between a very detailed bottom-up energy system model that assesses cost optimal configurations of the energy system, both at global and regional scales, with a reduced-form econometric model that takes into account key socio-economic factors for the electrification of the population. The same conceptual modelling framework has been applied in assessing long-term electrification rates in Sub-Saharan Africa [60] and it is extended in the current study to cover additional developing regions. Our methodology differs from the methodologies described above in the following aspects: a) the underlying energy system model, which is interfaced with the econometric model for electricity access, is a bottom-up cost optimisation model (in contrast to TIMER and IEA's models that are simulation models) and it has a detailed representation of the energy systems of 15 world regions; and b) we apply a reducedform econometric model that is estimated using polynomial distributed lags in order to take into account both short-term and long-term effects of key determinants for improving electricity access such as poverty, urbanisation, policy and institutional development for each developing region. To the best of our knowledge this type of modelling framework for electricity access has not yet been applied in literature for all developing regions.

Similar to the approaches presented in $[50,56,57,59,60]$, the modelling framework applied here is suitable to: a) investigate the critical components affecting the electrification rate of the population; b) assess the different energy supply and demand options; c) estimate the broader implications of increased electricity access on the energy system and on GHG emissions; and d) evaluate the effectiveness of policies and supports designed to achieve universal electricity access. Main strengths of the proposed framework are also: a) its transparency, since it is based on open source modelling using publicly available databases; b) its scalability that allows for higher regional detail to enable in-depth analysis; c) its generic interface, which enables the coupling of the econometric model for electricity access with different underlying energy system models.

The present work therefore makes a contribution to research in the direction of coupling large scale energy models with empirical models for estimating energy access, to assess not only future electrification rates of the population in developing regions but also to assess the broader impacts of increased electricity access on the energy system and environment (e.g. demand and supply mixes, investments, greenhouse gases emissions, energy system costs and energy prices). In addition to the methodological aspect, we also contribute to the literature regarding scenarios for increasing electricity access in the developing regions, complementing the studies presented by the International Energy Agency (IEA) in (e.g. Refs. [2-4]), by the International Institute for Applied Systems Analysis (IIASA) in (e.g. Refs. [53-55]), by the Netherlands' National Institute for Public Health and the Environment (RIVM) in (e.g. Refs. $[54,58,59]$ ) and by others (e.g. Ref. [48]). The two scenarios describe two different worlds, one with focus on low-cost energy in which the energy markets are fully liberalised and technologies compete on the basis of their production cost and resource availability; and a second one with a focus on sustainability in which the governments set the energy policies and promote technologies.

\subsection{Paper structure}

In section 2 we describe the two models applied in the study and their coupling. In section 3 we define the two WEC/PSI scenarios and we present their main assumptions regarding economic development, population and climate policy intensity.

In section 4 we focus on the outlook for electricity access in developing regions until 2030 under the assumptions of the WEC/PSI scenarios. We mainly discuss the drivers affecting the electrification of the population as they are assessed by both models. The electricity supply and demand, together with the electricity infrastructure investment requirements and production costs are provided by the 


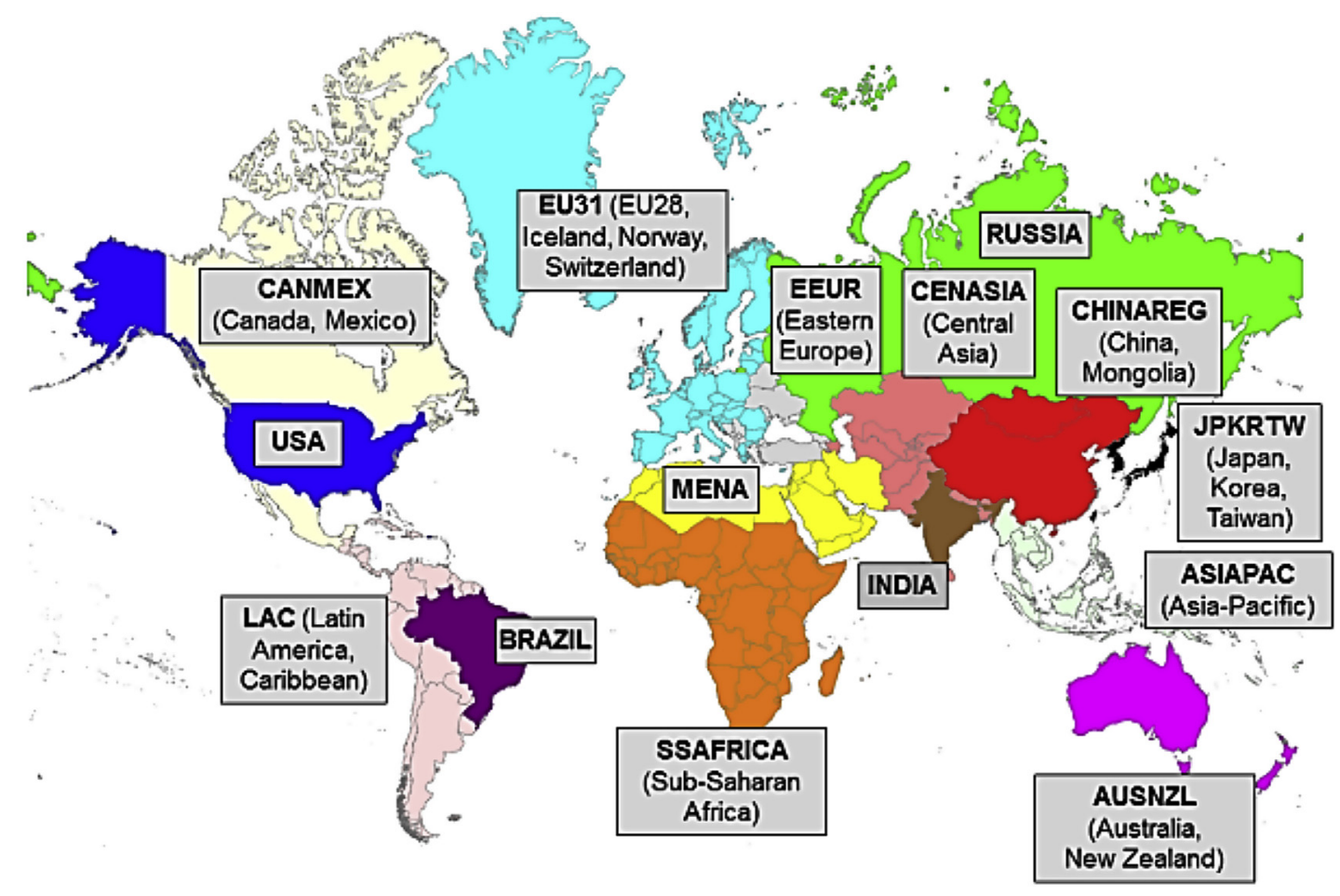

Fig. 3. The fifteen world regions in the GMM model.

energy system model. Additional key socio-economic determinants for increasing access to electricity, such as urbanisation, poverty, policy and institutional development, together with the estimation of the population with access to electricity, are provided by the reduced-form econometric model.

In section 5, we assess the additional effort in power generation infrastructure required in the two WEC/PSI scenarios to achieve the SE4All objective of universal electricity access by 2030 . Therefore, we examine two normative variants of the basic WEC/PSI scenarios, in which we set the SE4All target. We discuss the energy supply options, the power generation infrastructure investment requirements, and the implications of the universal electricity access case on $\mathrm{CO}_{2}$ emissions and energy demand. We conclude by assessing the robustness of our results through a series of sensitivity analyses: i) on the economic and demographic assumptions of the two WEC/PSI scenarios; ii) on the initial levels of electricity consumption for the newly connected population; and iii) on the transmission and distribution (T\&D) electricity grid extension costs.

\section{Modelling framework}

As mentioned in the introduction, two models are used in this study. The first model is the Global Multiregional MARKAL (GMM) model [61-64] belonging to the MARKAL family of models [65]. The GMM

\section{Resources (simplified)}

\section{Conversion Processes \\ (simplified)}

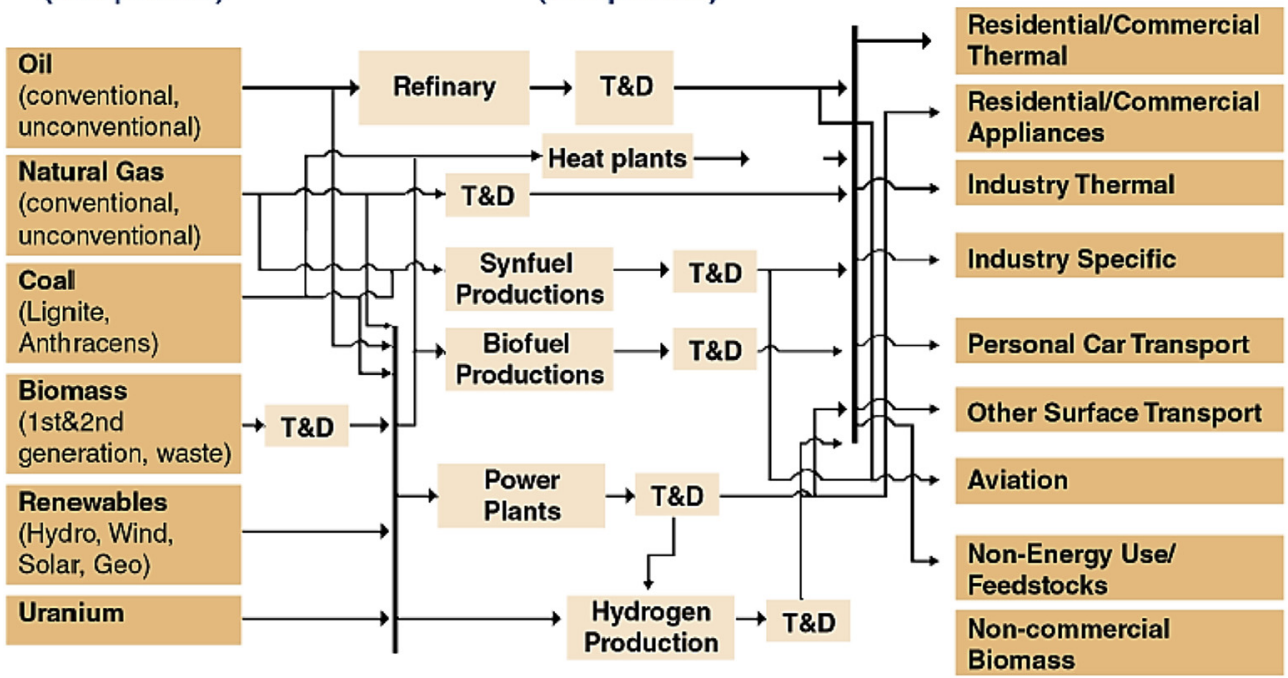

Fig. 4. A simplified Reference Energy System in GMM for a single region. 
model was used in assessing the development of the energy system. The second model is a regional reduced-form econometric model that estimates the population with access to electricity. The two models share common scenario assumptions regarding GDP and population projections. They are coupled at the electricity consumption in the residential sector as shown in Fig. 2 .

In the case of exploratory scenarios the GMM model first finds the cost-optimal configuration of the energy system. The calculated electricity consumption is then given to the econometric model as an input in order to project the electrification rate of the population together with the main drivers affecting it.

In the case of normative scenarios, the econometric model is used in a backward calculation to find the levels of useful energy demands in the residential/commercial sector that are necessary to meet the imposed electrification targets. This backward calculation requires an assumption regarding the initial electricity consumption level of the newly connected households. The updated demands are then fed back into the GMM model in order to calculate the least-cost pathway to achieve the desired electrification rates. The convergence of the two models can require a number of iterations, in which the useful energy demands calculated by the econometric model are adjusted such that the electricity consumption of the GMM model is sufficient to meet the universal electricity access target.

\subsection{The GMM model}

The GMM model is a linear programming perfect-foresight, bottomup, technology rich model, covering the period 2010 to 2100 with a time step of 10 years. The model computes an intertemporal partial equilibrium across all energy markets, under policy and technical constraints, by minimising the total energy system cost. The spatial resolution of GMM covers 15 world regions (Fig. 3), which have been defined according to criteria such as economic influence, level of economic development, energy resource endowments, level of intraregional integration, geography, policy and political situation [64]. The model represents more than 400 demand and supply technologies using the concept of the "Reference Energy System - RES" (Fig. 4), the dynamics of which are influenced by the scenario assumptions. International trade of energy carriers is also represented and subject to transportation costs.

The energy demand sectors in GMM are industry, residential/commercial, transport and non-energy uses. The energy demands in industrial and residential/commercial sectors are further disaggregated

Table 1

List of the variables used in the econometric model.

\begin{tabular}{|c|c|c|c|}
\hline Type of Variable & Variable Name & Unit & Source \\
\hline Input & Income & $\begin{array}{l}\text { Average income per capita } \\
\text { in USD2005 (PPP) }\end{array}$ & $\begin{array}{l}\text { IMF [66], World } \\
\text { Bank [67] }\end{array}$ \\
\hline Input & $\begin{array}{l}\text { Electricity } \\
\text { per capita }\end{array}$ & $\begin{array}{l}\text { Average } \mathrm{KWh} \text { per capita in } \\
\text { residential/commercial demand }\end{array}$ & IEA [68] \\
\hline Input & $\begin{array}{l}\text { Electrification } \\
\text { Programmes }\end{array}$ & $\begin{array}{l}\text { Targeted } \% \text { of population with } \\
\text { access to electricity }\end{array}$ & $\begin{array}{l}\text { IEA [2], World } \\
\text { Bank [5] }\end{array}$ \\
\hline Output & Urbanisation & $\%$ Of population in urban areas & UNPD [69] \\
\hline Output & Poverty & $\begin{array}{l}\text { \% Of population living with less } \\
\text { than } \$ 2 \text { (PPP 2005) per day }\end{array}$ & World Bank [67] \\
\hline Output & $\begin{array}{l}\text { Institutional } \\
\text { development }\end{array}$ & $\begin{array}{l}\text { Average of Country Policy and } \\
\text { Institutional Assessment (CPIA) } \\
\text { indices for public sector } \\
\text { management, economic } \\
\text { management, social inclusion } \\
\text { and structural policies }\end{array}$ & World Bank [67] \\
\hline Output & $\begin{array}{l}\text { Electricity } \\
\text { access }\end{array}$ & $\begin{array}{l}\% \text { Population with access } \\
\text { to electricity }\end{array}$ & $\begin{array}{l}\text { IEA [3], World } \\
\text { Bank [5], World } \\
\text { Bank [67], UNDP } \\
\text { WHO [70] }\end{array}$ \\
\hline
\end{tabular}

Box 1. Mathematical formulation of the econometric model:

Equation 1: Population with access to electricity:

$$
\begin{aligned}
& \ln \left(\text { elcaccess }_{r, t} /\left(1-\text { elcaccess }_{r, t}\right)\right) \\
& =\beta_{r, 0}+\beta_{r, 1} \cdot \sum_{k_{r}}\left(\gamma_{r, k_{r}, 1} \cdot \text { poverty }_{r, t-k_{r}}\right) \\
& \quad+\beta_{r, 2} \cdot \sum_{\lambda_{r}}\left(\gamma_{r, \lambda_{r}, 2} \cdot \text { urbanisation }_{r, t-\lambda_{r}}\right) \\
& \quad+\beta_{r, 3} \cdot \sum_{\mu_{r}}\left(\gamma_{r, \mu_{r}, 3} \cdot \text { elccap }_{r, t-\mu_{r}}\right)+a_{r, t}+\varepsilon_{r, t}
\end{aligned}
$$

Equation 2: Population living with less than \$2 PPP (2005) per day:

$$
\begin{aligned}
& \ln \left(\text { poverty }_{r, t} / \text { poverty }_{r, t-1}\right) \\
& =\beta_{r, 0}+\beta_{r, 1} \cdot \sum_{k_{r}}\left(\gamma_{k_{r}} \cdot \ln \left(\text { income }_{r, t-k_{r}} / \text { income }_{r, t-k_{r}-1}\right)\right) \\
& +\beta_{r, 2} \cdot \sum_{\lambda_{r}}\left(\gamma_{r, \lambda_{r}} \cdot \ln \left(\text { cpia }_{r, t-\lambda_{r}}\right)\right)+\varepsilon_{r, t}
\end{aligned}
$$

Equation 3: Country Policy and Institutional Assessment Index (CPIA):

$$
\begin{aligned}
\ln \left(c \operatorname{cpia}_{r, t} /\left(6-\operatorname{cpia}_{r, t}\right)\right)= & \beta_{r, 0}+\beta_{r, 1} \cdot \sum_{k_{r}}\left(\gamma_{k_{r}} \cdot g d p_{r, t-k_{r}}\right) \\
& +\varepsilon_{r, t}
\end{aligned}
$$

Equation 4: Percentage of internal migration of population from rural to urban areas:

$$
\begin{aligned}
& \ln \left(\text { migration }_{r, t} /\left(1-\text { migration }_{r, t}\right)\right) \\
& \quad=\beta_{r, 0}+\beta_{r, 1} \cdot \sum_{k_{r}}\left(\gamma_{k_{r}} \cdot \text { income }_{r, t-k_{r}}\right)+\varepsilon_{r, t}
\end{aligned}
$$

Equation 5: Percentage of urban population in total population:

$$
\begin{aligned}
\text { urbanisation }_{r, t}= & \text { urbanisation }_{r, t-1} \cdot\left(\text { pop }_{r, t} / \text { pop }_{r, t-1}\right) \\
& + \text { migration }_{r, t} \cdot \text { pop }_{r, t} \cdot\left(\left(\operatorname{pop}_{r, t-1}\right.\right. \\
& \left.\left.- \text { urbanisation }_{t-1}\right) / \operatorname{pop}_{r, t-1}\right)
\end{aligned}
$$

to thermal and specific uses. Transport includes subsectors for private passenger transport, aviation and other surface transport. The energy demand technologies operate at the level of useful energy. The useful energy demands are derived from the scenario assumptions based on a coherent storyline. The GMM model supplies the useful energy demand by optimising the endogenous equipment choice and the corresponding production and delivery of energy carriers.

\subsection{Econometric model for estimating the population with access to electricity}

In order to forecast the population with access to electricity in the WEC/PSI scenarios, we have developed a reduced-form regional econometric model with the same spatial resolution as in GMM. The model takes a number of variables into account that have been 
\% Population with Access to Electricity

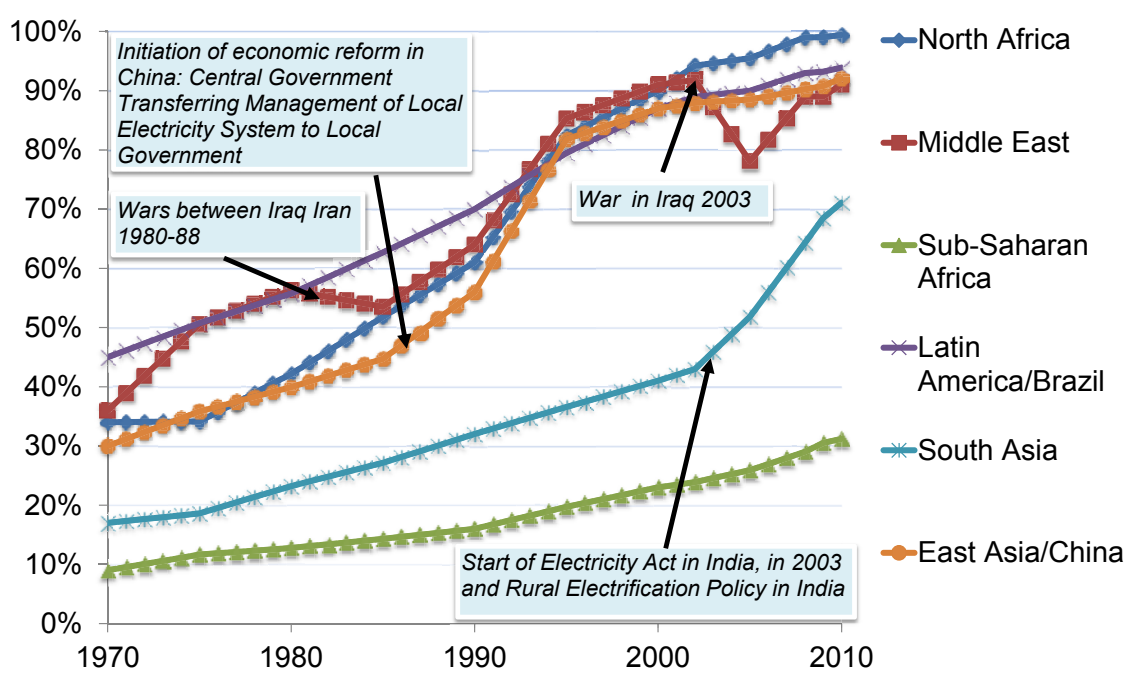

Fig. 5. Historical evolution of the population electrification rates in selected world regions (source: IEA world energy outlooks and own compilation).

identified in the literature as statistically significant in affecting the electrification rate of the population, and - at the same time - they can be linked with the results obtained from the GMM model and the WEC/PSI scenarios assumptions. The electrification programmes promoting energy access, though in general neither sustainable nor adequately contributing to development [10], are included in the model specification as exogenous adjustments that shift the curve for the rate of electrification of the population towards the expected outcomes foreseen by these programmes (Equation (1)). The model was estimated using time-series for the period 1970-2012. The short- and long-term effects of the explanatory variables are captured with distributed lag estimation ${ }^{5}$ [71,72]. Table 1 summarises the input and output variables of the model for each region, together with the data sources used in the estimation.

The mathematical formulation of the econometric model is given in Box 1. Equation (1) projects the population electrification rate (elcacc $_{r, t}$ ) in region $r$ and time $t$ as a function of the percentage of population living with less than $\$ 2$ per day $\left(\right.$ poverty $\left._{r, t}\right)$, the population urbanisation rate (urbanisation $_{r, t}$ ) and the average electricity per capita in residential sector ${ }^{6}\left(\right.$ elccap $\left._{r, t}\right)$. This is a sigmoid function representing increasing efforts to electrify the remaining segments of the population living in small or dispersed communities, often with low income levels. This is also justified by the fact that the electricity supply in remote rural areas is characterised by peaky electricity consumption profiles, and therefore it can be up to seven times more costly compared to urban settings [73]. Thus, utilities are reluctant to serve these areas unless remote consumers are able or willing to pay at least for operating costs [74]. The equation also includes an exogenous adjustment factor $\left(a_{r, t}\right)$ to account for electrification programmes. This

\footnotetext{
${ }^{5}$ A simplified equation for PDL is $y_{t}=a+b(L) x_{t}+u_{t}=a+\sum b_{s} x_{t-s}+u_{t}$ where $u_{t}$ is the stationary error term. This form is very similar to the infinite-moving-average representation of an ARMA process, except that the lag polynomial on the right-hand side is applied to the explanatory variable rather than to a white-noise process. The individual coefficients $b_{s}$ are called lag weights and they collectively comprise the lag distribution, constrained to lie on a polynomial of known degree. They define the pattern of how $x$ affects $y$ over time.

6 The average electricity consumption per capita is linked with the results from the GMM model and it is influenced by energy prices and taxes, population and total electricity consumption in the residential sector.
}

factor can shift the curve of the share of population with electricity access upwards, reflecting in this way the expected outcomes of electrification support policies in place. Fig. 5 presents the historical trends in population electrification in various world regions, in which the sigmoid shape of the electrification rate can be observed in almost all regions.

Equation (2) projects the population living with less than $\$ 2$ per day (poverty $y_{r, t}$ ) as a function of the average per capita income (income $e_{r, t}$ ) and the Country Policy and Institutional Assessment (CPIA) index $\left(c p i a_{r, t}\right)$ that is used as a proxy for the government effectiveness and corruption. ${ }^{7}$ Equation (3) links the CPIA index with the GDP $\left(g d p_{r, t}\right)$ in region $r$. Equation (4) forecasts the percentage of population migrating from rural to urban areas $\left(\right.$ migration $_{r, t}$ ) due to income differences. Equation (5) projects the urbanisation rate of the population (urbanisation $_{r, t}$ ) based on the work of [75] and the theory of population mobility presented in Ref. [76].

In all equations described above, the coefficients $\beta_{r, i}$ are the ordinary least squares (OLS) estimators and the terms $\varepsilon_{r, t}$ are the error of the regressions. The coefficients of a polynomial distribution lag $i$ with degree $\kappa_{r}$ are denoted as $\gamma_{r, \kappa_{r}, i}$. Where necessary the econometrically estimated equations include an additional term for first order autocorrelation correction. Table 2 presents the estimated coefficients obtained, ${ }^{8}$ together with their statistical significance ( $p$-values).

\section{WEC/PSI global energy scenarios: "Jazz" and "Symphony"}

The WEC/PSI global energy scenarios have been built through a number of workshops in collaboration with a range of partners and stakeholders including international energy suppliers and energy technology companies from WEC's extended network of 93 member committees and 3000 member organisations. Table 3 gives a short overview of the two scenarios and the interested reader is directed to [8] for additional information. Further to the WEC/PSI scenarios we examine two normative variants aimed at achieving universal electricity access by 2030 in section 5 . In the same section additional

\footnotetext{
7 The CPIA index has a scale from $1=$ worse to $6=$ best [67].

8 The sum of lags is reported for the polynomial distribution lags, which corresponds to the total elasticity.
} 
Table 2

Estimated coefficients and their corresponding $\mathrm{p}$-values for each equation and region.

\begin{tabular}{|c|c|c|c|c|c|c|c|c|c|c|c|c|c|}
\hline & C & p-val & POV & p-val & URB & p-val & ELC & p-val & INC & p-val & CPIA & p-val & $\mathrm{R}-\mathrm{sq}$ \\
\hline \multicolumn{14}{|l|}{ Pacific Asia } \\
\hline Eq. (1): Electricity access & & & -0.990 & 0.000 & 0.988 & 0.005 & 2.687 & 0.000 & & & & & 0.964 \\
\hline Eq. (2): Poverty & & & & & & & & & -0.277 & 0.043 & -0.026 & 0.084 & 0.812 \\
\hline Eq. (3). Institutional development & & & & & & & & & 0.055 & 0.000 & & & 0.431 \\
\hline Eq. (4). Population migration & 0.008 & 0.000 & & & & & & & 0.001 & 0.016 & & & 0.753 \\
\hline \multicolumn{14}{|l|}{ Central Asia } \\
\hline Eq. (1): Electricity access & & & -3.520 & 0.000 & 1.891 & 0.007 & 8.070 & 0.000 & & & & & 0.915 \\
\hline Eq. (2): Poverty & & & & & & & & & -0.225 & 0.005 & -0.012 & 0.000 & 0.754 \\
\hline Eq. (3). Institutional development & & & & & & & & & 0.176 & 0.000 & & & 0.609 \\
\hline Eq. (4). Population migration & -0.003 & 0.000 & & & & & & & 0.007 & 0.000 & & & 0.866 \\
\hline \multicolumn{14}{|l|}{ India } \\
\hline Eq. (1): Electricity access & & & -2.574 & 0.000 & 2.571 & 0.009 & 10.461 & 0.000 & & & & & 0.999 \\
\hline Eq. (2): Poverty & 0.567 & 0.001 & & & & & & & -0.184 & 0.064 & -0.450 & 0.001 & 0.857 \\
\hline Eq. (3). Institutional development & & & & & & & & & 0.387 & 0.000 & & & 0.746 \\
\hline Eq. (4). Population migration & 0.004 & 0.000 & & & & & & & 0.002 & 0.000 & & & 0.699 \\
\hline \multicolumn{14}{|l|}{ Latin America } \\
\hline Eq. (1): Electricity access & & & -3.238 & 0.000 & 1.665 & 0.000 & 3.156 & 0.000 & & & & & 0.953 \\
\hline Eq. (2): Poverty & & & & & & & & & -1.521 & 0.026 & -0.039 & 0.022 & 0.778 \\
\hline Eq. (3). Institutional development & & & & & & & & & 0.068 & 0.000 & & & 0.650 \\
\hline Eq. (4). Population migration & & & & & & & & & 0.002 & 0.000 & & & 0.559 \\
\hline \multicolumn{14}{|l|}{ Middle East \& North Africa } \\
\hline Eq. (1): Electricity access & & & -0.899 & 0.097 & 0.421 & 0.005 & 1.754 & 0.000 & & & & & 0.936 \\
\hline Eq. (2): Poverty & & & & & & & & & -2.107 & 0.000 & & & 0.897 \\
\hline Eq. (3). Institutional development & & & & & & & & & 0.013 & 0.001 & & & 0.537 \\
\hline Eq. (4). Population migration & 0.001 & 0.093 & & & & & & & 0.002 & 0.000 & & & 0.938 \\
\hline \multicolumn{14}{|l|}{ Sub-Saharan Africa } \\
\hline Eq. (1): Electricity access & & & -3.393 & 0.000 & 1.701 & 0.000 & 5.425 & 0.000 & & & & & 0.998 \\
\hline Eq. (2): Poverty & 0.779 & 0.027 & & & & & & & -0.145 & 0.010 & -0.692 & 0.027 & 0.879 \\
\hline Eq. (3). Institutional development & & & & & & & & & 0.061 & 0.000 & & & 0.595 \\
\hline Eq. (4). Population migration & & & & & & & & & 0.005 & 0.000 & & & 0.943 \\
\hline
\end{tabular}

$\mathrm{C}=$ Constant

$\mathrm{POV}=$ Population living with less than $\$ 2$ per day.

$\mathrm{URB}=$ urbanisation

$\mathrm{ELC}=$ Electricity consumption per capita in residential.

INC = Average GDP per capita.

$\mathrm{CPIA}=$ Country policy and institutional assessment index.

$\mathrm{p}$-val $=\mathrm{p}$-value.

Table 3

The WEC/PSI scenarios at a glance.

Jazz Symphony

Focus on economic growth via low cost energy and using the best available resources:

- Economy liberalisation, opening of upstream energy markets, increased

Focus on environmental sustainability and energy security:

participation of the private sector $\rightarrow$ high economic growth

- Market regulation with policies set by governments, energy policies financed and coordinated by governments, regulatory hurdles, limited Foreign Direct Investments (FDI) and limited participation of the private sector into the economy

$\rightarrow$ lower economic growth than "Jazz"

- Medium fertility in line with UN Population Division; lower incomes result in higher opportunity costs for raising children for women

Lower fertility is driven by higher incomes and education that reduce the

opportunity cost for raising children for women

- Technology choice is based on energy markets: limited government support for nuclear, CCS, large hydro, renewables

- Energy efficiency is market driven

- Delayed climate policy action with no global agreements and diverse

- Technology choice is driven by energy policies implemented by governments: increased

- Efficiency measures polices are implemented by governments

- Strong climate policy with global convergence; emission trading schemes are developed regional responses by 2030 , which are replaced by a global $\mathrm{CO}_{2}$ market in the longer term

sensitivity analyses of these two normative variants are also considered regarding: i) the economic and demographic assumptions of the two scenarios; ii) the initial electricity consumption levels for the newly connected population; and iii) the T\&D electricity grid expansion costs.

Table 4 presents the assumptions regarding GDP and population in the developing regions in the WEC/PSI scenarios. The future economic growth shifts from developed countries to developing economies and it is assumed that developing regions implement structural economic reforms that also lift domestic constraints related to monetary and fiscal policies. Infrastructure investments and improved labour relations increase foreign direct investments (FDI) and buoyant services and at the same time contribute to increased integration of developing regions into the global value chains. Although the main drivers for the economic development are common in the two scenarios, the assumed GDP growth in "Jazz" and "Symphony" is not the same because of the different market structures (liberalisation versus regulation), which affect the participation of the private sector into the economy, the FDI infusions and the capital and labour flows.

The assumptions on population growth are based on the premise that higher incomes and education levels facilitate women's access to the labour market and result in increased opportunity costs of raising children. Compared to the UNPD population projections [69], "Jazz" is 
Table 4

GDP per capita and population assumptions in "Jazz" and "Symphony".

\begin{tabular}{|c|c|c|c|c|c|c|c|}
\hline \multirow[b]{2}{*}{$\begin{array}{l}\text { GDP per capita } \\
\text { (\$2010 MER) }\end{array}$} & \multirow[b]{2}{*}{2010} & \multicolumn{3}{|l|}{ Jazz } & \multicolumn{3}{|c|}{ Symphony } \\
\hline & & 2020 & 2030 & $2010-2030$ & 2020 & 2030 & $2010-2030$ \\
\hline Pacific Asia & 3150 & 6380 & 10,470 & $6.2 \%$ & 5690 & 8620 & $5.2 \%$ \\
\hline Central Asia & 1340 & 2040 & 3430 & $4.8 \%$ & 1910 & 2950 & $4.0 \%$ \\
\hline India & 1330 & 2270 & 4230 & $6.0 \%$ & 2080 & 3500 & $5.0 \%$ \\
\hline Latin America & 6190 & 8810 & 12,230 & $3.5 \%$ & 8310 & 10,930 & $2.9 \%$ \\
\hline $\begin{array}{l}\text { Middle East \& North } \\
\text { Africa }\end{array}$ & 6650 & 7690 & 9940 & $2.0 \%$ & 7510 & 9300 & $1.7 \%$ \\
\hline Sub-Saharan Africa & 1350 & 1680 & 2530 & $3.2 \%$ & 1620 & 2280 & $2.7 \%$ \\
\hline $\begin{array}{l}\text { Average in the above } \\
\text { regions }\end{array}$ & 2508 & 3721 & 5704 & $4.2 \%$ & 3470 & 4917 & $3.4 \%$ \\
\hline Population (millions) & 2010 & 2020 & 2030 & $2010-30$ & 2020 & 2030 & $2010-30$ \\
\hline Pacific Asia & 604 & 664 & 707 & $0.8 \%$ & 669 & 721 & $0.9 \%$ \\
\hline Central Asia & 475 & 545 & 600 & $1.2 \%$ & 551 & 618 & $1.3 \%$ \\
\hline India & 1225 & 1374 & 1485 & $1.0 \%$ & 1387 & 1523 & $1.1 \%$ \\
\hline Latin America & 278 & 309 & 333 & $0.9 \%$ & 312 & 342 & $1.0 \%$ \\
\hline $\begin{array}{l}\text { Middle East \& North } \\
\text { Africa }\end{array}$ & 381 & 442 & 490 & $1.3 \%$ & 448 & 507 & $1.4 \%$ \\
\hline Sub-Saharan Africa & 857 & 1070 & 1281 & $2.0 \%$ & 1089 & 1354 & $2.3 \%$ \\
\hline $\begin{array}{l}\text { Total in the above } \\
\text { regions }\end{array}$ & 3819 & 4405 & 4897 & $1.3 \%$ & 4456 & 5066 & $1.4 \%$ \\
\hline
\end{tabular}

Table 5

Correlations between electricity access and its key drivers based on time series analysis over the period 1970-2012.

\begin{tabular}{lllll}
\hline & Poverty & Urbanisation & CPIA Index & $\begin{array}{l}\text { Electricity } \\
\text { per capita }\end{array}$ \\
\hline Pacific Asia & -0.96 & 0.99 & 0.89 & 0.98 \\
Central Asia & -0.97 & 0.97 & 0.34 & 0.58 \\
India & -0.97 & 0.99 & 0.98 & 0.96 \\
Latin America & -0.41 & 0.99 & 0.76 & 0.96 \\
Middle East and North Africa & -0.68 & 0.83 & 0.74 & 0.77 \\
Sub-Saharan Africa & -0.82 & 1.00 & 0.45 & 0.83 \\
\hline
\end{tabular}

close to the "Low Fertility" variant, while "Symphony" is close to the "Medium Fertility" variant.

The climate policy intensity in the developing regions is very modest in "Jazz" reaching $\$ 5$ per tonne of $\mathrm{CO}_{2}$ in $2030 .{ }^{9}$ In "Symphony" it is assumed that the developing regions join the international effort led by the developed countries in the longer-term and the $\mathrm{CO}_{2}$ price is $\$ 23$ per tonne of $\mathrm{CO}_{2}$ in 2030 [8]. The same $\mathrm{CO}_{2}$ prices are applied to all energy demand sectors in both scenarios.

\section{Outlook for electricity access in "Jazz" and "Symphony" in 2030}

In this section an outlook is presented regarding the population's access to electricity in the exploratory WEC/PSI scenarios for the developing countries until 2030. As already mentioned in the methodology section, the GMM model finds the cost-optimal configuration of the energy system. Subsequently, the econometric model, which takes the electricity consumption from GMM as an input, provides results for key socio-economic drivers affecting the households' electrification and the population with access to electricity in each region. Therefore, we first discuss the outlook for the key factors affecting electricity access, and then we present the projection of the population that still remains without electricity access in 2030.

\footnotetext{
${ }^{9}$ All monetary units in the current text refer to real US Dollars of 2010.
}

\subsection{Development of the key drivers of electricity access until 2030}

Based on the literature we have identified as the main drivers for affecting electricity access, the electricity consumption per capita (which in turn is influenced by the electricity supply mix and the cost of the delivered energy to consumers) and a number of socio-economic indicators such as the population living with less than \$2 PPP (2005) per day, the urbanisation rate and the policy effectiveness (CPIA index). The assessment of the electrification of the households requires the application of the coupled framework due to the multitude of determinants. As already stated, the GMM model provides the energy system configuration together with the electricity consumption per capita, while the econometric model provides the development of the rest of the socio-economic drivers and the ultimately the population electrification rates.

The correlations of these drivers with the electricity access are presented in Table 5 . Poverty is negatively correlated with electricity access, as more than $80 \%$ of the people without access to electricity are living in the poorest regions. The correlation with urbanisation is positive, since around $85 \%$ of the population without access to electricity live in rural areas. The CPIA Index is also positively correlated with electricity access with higher correlations suggesting higher probability of success of national electrification programmes. Finally, the correlation with the average electricity consumption per capita is also positive, with stronger correlations implying higher levels of energy equity.

\subsubsection{Urbanisation}

Fig. 6 presents the urban population in developing Pacific Asia, India, Central Asia, developing Latin America, Sub-Saharan Africa, Middle East and North Africa by 2030. In "Jazz" the urban population increases by 873 million people from 2010 to 2030 . More than half of this increase, around 495 million people, is attributable to internal migration from rural to urban areas because of income disparity. In "Symphony" the urban population increases by 889 million people between 2010 and 2030, of which 477 million people migrate from rural to urban areas. The urbanisation rate in "Symphony" is lower than in "Jazz" because of the lower economic growth. In both scenarios, much of the increase in urban population takes place in Sub-Saharan Africa and India implying significant challenges in meeting the needs of housing and urban support infrastructure in these regions.

\subsubsection{Poverty}

Poverty is reduced in both scenarios due to the positive economic development (Fig. 7). The number of people who are living with less than \$2 PPP per day declines from 1947 million in 2010 to 1047 million in "Jazz" and 1163 million in "Symphony" by 2030. In both scenarios much of the reduction in poverty occurs in developing Asia and particularly in India. On the other hand, in Sub-Saharan Africa the growth of the population absorbs the economic growth and the remaining poor population in the world becomes increasingly concentrated in this region: half of the poor population worldwide lives in Sub-Saharan Africa in 2030 in both scenarios.

\subsubsection{Policy and institutional development}

Table 6 presents the projections of the Country Policy and Institutional Assessment (CPIA) index ${ }^{10}$, reflecting developments in the quality of public management, as well as the implementation of

\footnotetext{
10 Projections of the CPIA index were obtained from equation (3), which was calibrated to the projections of the International Futures modelling system of the University of Denver [77]. This takes into account factors other than the economic development, which are not fully captured by our modelling framework, such as political stability, economic and structural reforms already implemented and in progress etc.
} 


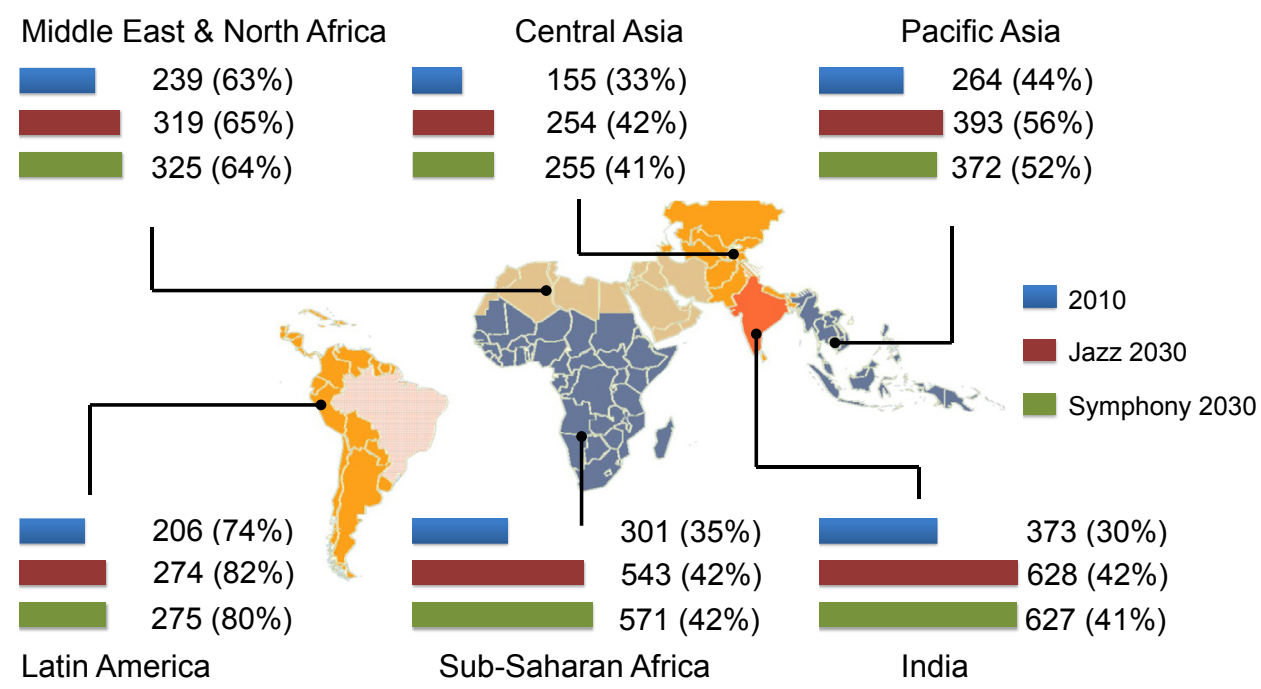

Fig. 6. Urban population by region and scenario, in millions and as \% of region's total population.

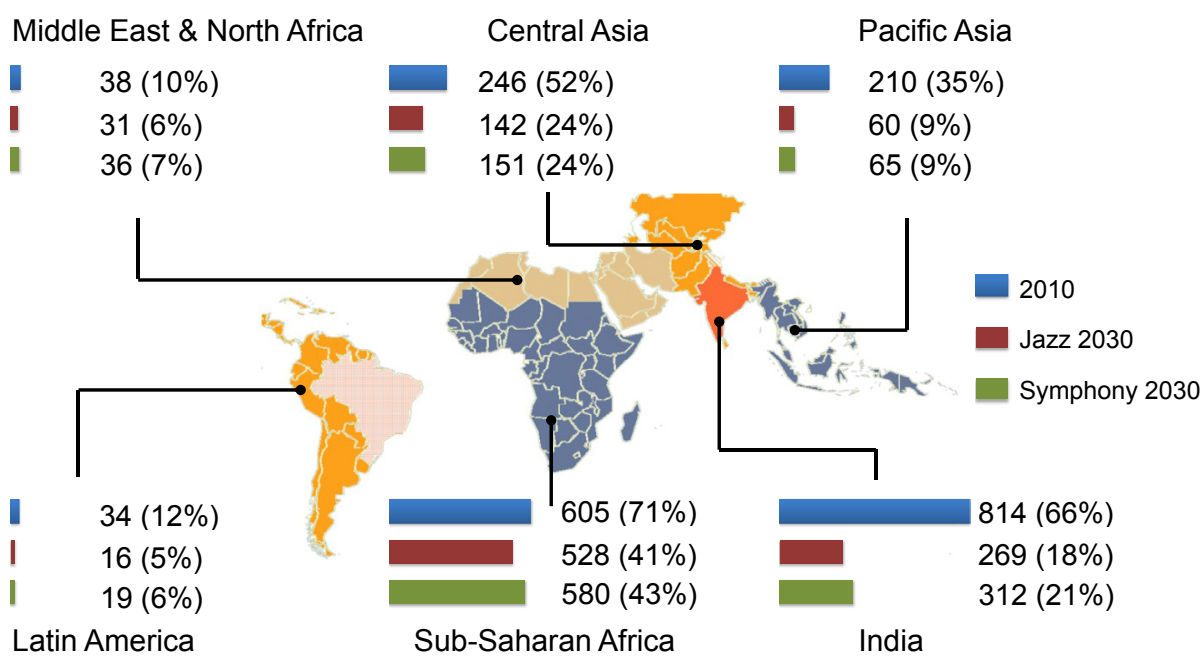

Fig. 7. Population living with less than $\$ 2(2005$, PPP) per day, in millions and as $\%$ of region's total population.

economic and social structural changes. In both scenarios the index improves in all regions, implying a reduction in corruption and an increase in the efficiency of public administration.

\subsubsection{Electricity demand and supply}

In both WEC/PSI scenarios the final electricity consumption in developing regions doubles in 2030 relative to 2010 levels, growing on average by $4.1 \%$ p.a. in "Jazz" and $3.8 \%$ p.a. in "Symphony" (Fig. 8). More than the half of this growth takes place in residential and commercial sectors because of the increased use of electric

\begin{tabular}{|c|c|c|c|c|c|}
\hline \multirow[b]{2}{*}{ CPIA ( $1=$ worst, $6=$ best $)$} & \multirow[b]{2}{*}{2010} & \multicolumn{2}{|l|}{ Jazz } & \multicolumn{2}{|c|}{ Symphony } \\
\hline & & 2020 & 2030 & 2020 & 2030 \\
\hline Pacific Asia & 3.30 & 3.40 & 3.69 & 3.37 & 3.56 \\
\hline Central Asia & 3.32 & 3.41 & 3.72 & 3.39 & 3.62 \\
\hline India & 3.72 & 4.04 & 4.84 & 3.98 & 4.60 \\
\hline Latin America & 3.61 & 3.73 & 4.01 & 3.71 & 3.91 \\
\hline Middle East \& North Africa & 3.07 & 3.13 & 3.15 & 3.12 & 3.14 \\
\hline Sub-Saharan Africa & 3.12 & 3.16 & 3.19 & 3.16 & 3.18 \\
\hline
\end{tabular}

appliances at the expense of traditional fuels (e.g. kerosene, noncommercial biomass). Average electricity consumption per capita in the residential and commercial sectors reaches $858 \mathrm{kWh}$ in "Jazz" and $760 \mathrm{kWh}$ in "Symphony" in 2030 compared to $531 \mathrm{kWh}$ in 2010. The electrification rate of final energy demand is on average higher in "Symphony" than in "Jazz" (16.7\% versus $13.8 \%)$. This is driven by the emphasis on efficiency and the stronger climate policy assumed in this scenario, which increase the use of electricity in the demand sectors.

The electricity supply mix in the two scenarios reflects underlying energy policies and market structures (Fig. 9). In "Jazz" investments in power generation are towards flexible projects with short construction times. Capital intensive projects, such as nuclear and hydropower, are not financially attractive. In the absence of supporting policies, solar and wind power are competitive only in regions with good resource quality ensuring high utilisation rates. In "Jazz", each region tries to make the best possible use of available resources with the lowest possible cost: coal dominates electricity production in India and Central Asia; gas is a major fuel for electricity supply in the Middle East \& North Africa; gas becomes important for Latin America due to limited investment in hydropower; and coal and gas are the main options for electricity supply in Pacific Asia and Sub-Saharan Africa. 


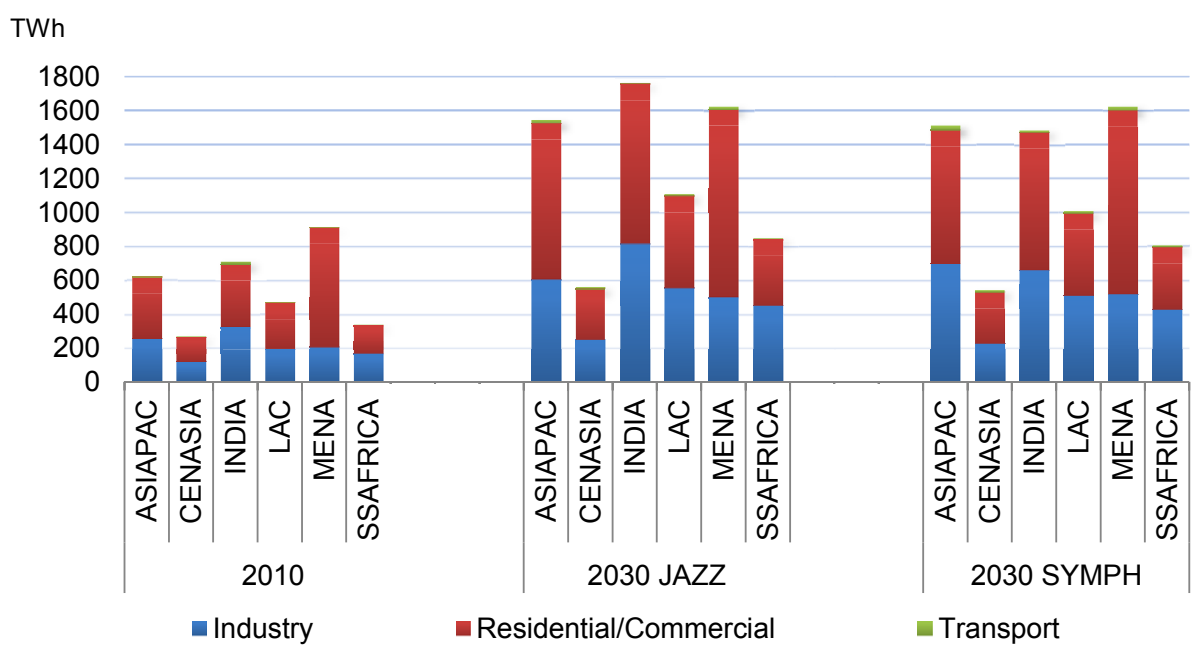

Fig. 8. Electricity consumption by region and sector.

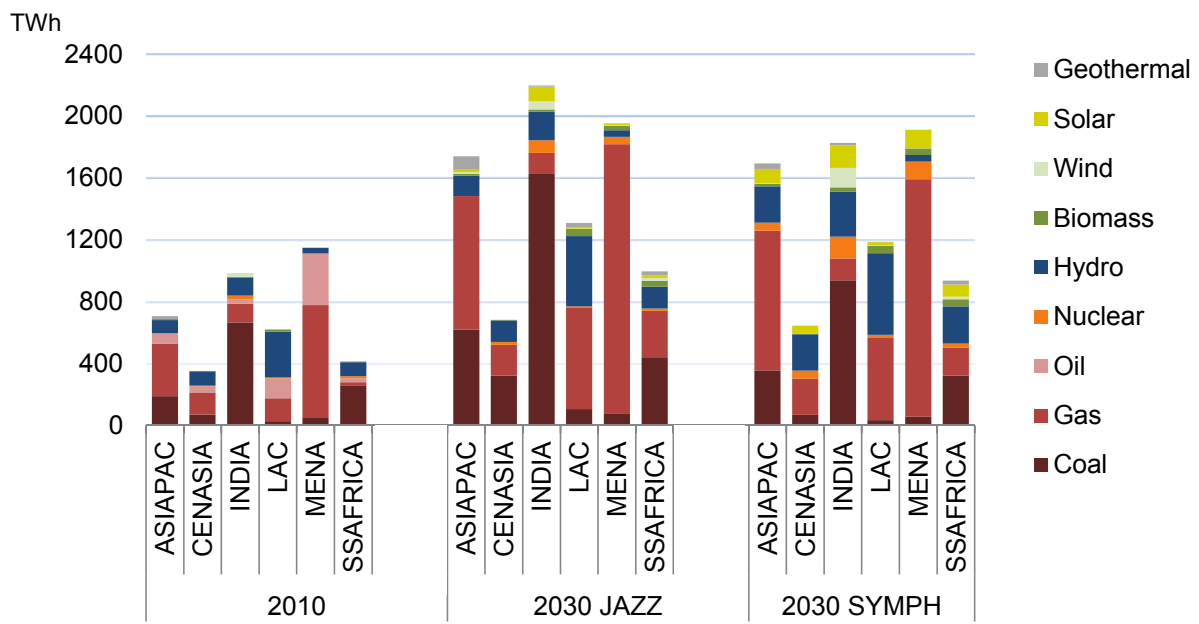

Fig. 9. Electricity generation mix by fuel and region.

On the other hand, the electricity generation mixes in the "Symphony" scenario are more uniform across regions and more diversified in terms of technology choice than in the "Jazz" scenario. Low-carbon technologies account for a share in total electricity production from $17 \%$ (in the Middle East) to $53 \%$ (in Latin America) in 2030, driven by effective climate policy and the presence of supportive measures (e.g. subsidies). Solar based generation is more competitive than wind, as it is an off-grid solution with high utilisation rates in developing regions.

The investments in new power generation capacity and grid expansion are significant in both scenarios (Fig. 10). In "Jazz", around $1265 \mathrm{GW}$ of new capacity is added over the period of 2011-2030, with India accounting for around one third of it. The annual undiscounted investment expenditure in "Jazz" sums up to $\$ 165$ billion, of which $\$ 94$ billion are directed to new power generation capacity and $\$ 71$ billion in electricity T\&D grid expansion and refurbishment. ${ }^{11}$ It should be noted

\footnotetext{
11 The MARKAL family of models does not have a spatial representation of the grid. The model assumes that grid expansion occurs when $1 \mathrm{GW}$ of new capacity is added to the electricity system. In our analysis we also adjusted the investment costs for electricity grid expansion to reflect different population densities of developing regions based on data provided from IEA [3]. The investment costs for electricity grid expansion are shown in Table 7.
}

that the electricity power plants specific investment costs (Table 7) are different in the two scenarios because of different technology learning dynamics arising from the endogenous learning by experience mechanism of the model [65].

In "Symphony", around 1429 GW of new capacity is installed between 2011 and 2030, with one quarter of it in India. The annual undiscounted investment expenditure over the period of 2011-2030 sums up to $\$ 208$ billion, of which $\$ 131$ billion are invested in new generation capacity and $\$ 77$ billion in electricity T\&D grid. The "Symphony" scenario is more expensive than "Jazz" because of its capital intensive pathway towards long term environmental sustainability.

\subsection{Population without access to electricity in 2030}

The population with electricity access increases in both scenarios because of positive developments in the key drivers affecting it (as discussed in the previous section) and the electrification programmes in place (Table 8 presents an overview of the electrification programmes taken into account in the current study). In the WEC/PSI scenarios we do not consider additional policies to expand energy access other than those in place today. However, as it is mentioned by both [2] and [10], while the adoption of national targets and 

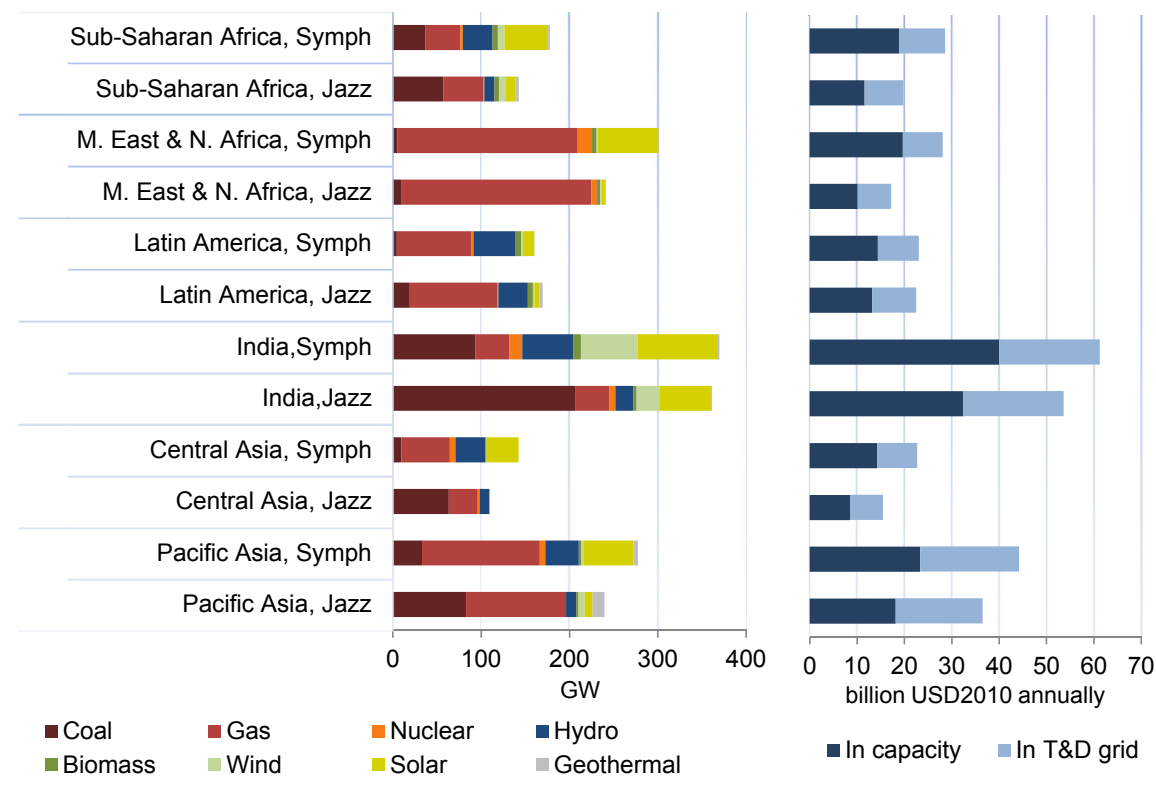

Fig. 10. Cumulative investment in capacity (left) and annual expenditure (right), 2011-2030.

programmes for electricity access is important, in practice it has been relatively commonplace for initial ambitions to be subsequently downgraded.

It should be noted that the prospects of improvement in electricity access is fragile in both scenarios: it can still be upset by changes in economic development, higher energy prices or the failure to implement policy actions to increase electrification rates of the population. Therefore, we also perform sensitivity analyses regarding the GDP and population growth in the next section, in order to assess the robustness of our projections regarding the population with access to electricity and the required investment in power generation infrastructure to support increased levels of electricity access.

In both scenarios Latin America and the Middle East and North Africa achieve universal electricity access by 2030 , while developing Asia and Sub-Saharan Africa continue to have a significant electricity access

Table 7

Specific investment costs in electricity infrastructure assumed in the present study, USD2010.

\begin{tabular}{lrrc}
\hline T\&D expansion costs in \$/kWe & & $2010-2030$ \\
\hline Asia Pacific & & 1399 \\
Central Asia & & 842 \\
India & & 674 \\
Latin America & & 999 \\
Middle East and North Africa & & 978 \\
Sub-Saharan Africa & & & 1177 \\
\hline & & Jazz & Symphony \\
\cline { 4 - 5 } & 2010 & 2030 & 2030 \\
\hline Specific investment cost \$/kWe & 686 & 627 & 657 \\
\hline Gas turbine combined cycle & 1473 & 1473 & 1473 \\
Coal conventional & 2222 & 2222 & 2222 \\
Coal advanced & 3015 & 3015 & 3015 \\
Hydro (average of different scales) & 3296 & 1732 & 2430 \\
Solar PV & 1370 & 1262 & 1370 \\
Wind turbines & 1052 & 1052 & 1052 \\
CHP gas & 6486 & 4410 & 4410 \\
Geothermal & 3717 & 3717 & 3717 \\
Biomass thermal & 3144 & 2990 & 3121 \\
Biomass gasification & 2805 & 2805 & 2805 \\
\hline Nuclear power (average of regions) & & & \\
\hline
\end{tabular}

deficit (Fig. 11). In the "Jazz" scenario around 733 million people lack access to electricity in 2030. In developing Asia the number of people without access to electricity is halved, going from around 605 million in 2010 to 275 million in 2030. India accounts for a large proportion of the increased access to electricity, continuing an already positive trend initiated by its rural electrification programmes. However, India is still the country with the largest population without electricity access in 2030. In Sub-Saharan Africa the number of people without access to electricity is reduced only by 134 million, and this reduction is achieved mainly after 2020 .

In the "Symphony" scenario the global electrification rate of the population is slightly lower than in "Jazz". The population growth in "Symphony" outpaces the number of new electricity connections. At the same time the expansion of the infrastructure required to provide electricity access to large parts of the rural population is hampered by the lower economic growth assumed in this scenario. As a result, around $\mathbf{8 8 5}$ million people still lack access to electricity in 2030 in "Symphony". Much of the reduction in the number of people without access to electricity occurs in developing Asia. On the other hand, in Sub-Saharan Africa the population lacking access to electricity reduces by only 47 million between 2010 and 2030.

The trajectories in the population electrification between developing Asia and Sub-Saharan Africa are different in the WEC/PSI scenarios. While developing Asia achieves electrification rates above $60 \%$, Sub-Saharan Africa accounts for more than $60 \%$ of the global population without electricity access in 2030 in both scenarios. Some of the contributing factors that could explain the high concentration of the remaining global population without access in Sub-Saharan Africa include: a) the current state of electricity infrastructure; b) the nature and the extent of expected flows of investment to different parts of the power sector; c) the large size of many African countries; and d) demographic stress due to the high population growth rate that outpaces the growth of new electricity connections.

The size of the challenge that remains in our projections in both scenarios should not obscure the progress that is being made. The annual investment expenditure in power generation infrastructure that is directed to increase electricity access at a global scale amounts to close to \$16 billion in "Jazz" and \$18 billion in "Symphony" over the 
Table 8

Major electrification programmes and targets for improving electricity access, taken into account in WEC/PSI scenarios (source IEA [2]).

\begin{tabular}{lll}
\hline Country & Programme name & Objective \\
\hline North \& South Latin America & Enabling Electricity - ENEL & Implementing more than 30 projects in 20 Latin America Countries to improve electricity \\
& & access in isolated communities [78] \\
Brazil & Luz para Todos & Aiming at increasing rural electrification in Brazil (2003-2014) [79] \\
India & Rajiv Gandhi Grameen Vidyutikaran Programme & Electrification of more than 17 million rural households [80] \\
Bangladesh & Master Plan for Electrification & Electricity for all by 2020 [81] \\
Nepal & Rural Electrification Programme & Electricity for all by 2027 [82] \\
Philippines & Philippines Energy Plan & Electrification of $90 \%$ of households by 2017 [83] \\
Indonesia & Rural Electrification Programmes & Electricity access for $95 \%$ of the population by 2020 [84] \\
Vietnam & National energy development programme & Universal electrification by 2020 [85] \\
Ghana & National Electrification Scheme & $100 \%$ Electricity access by 2020 [86] \\
South Africa & Integrated National Electrification Programme & $100 \%$ Electricity access by 2020 [87] \\
Zambia & Rural Electrification Master Plan & Electricity access for 78\% in urban and 15\% in rural areas by 2015 [88]
\end{tabular}

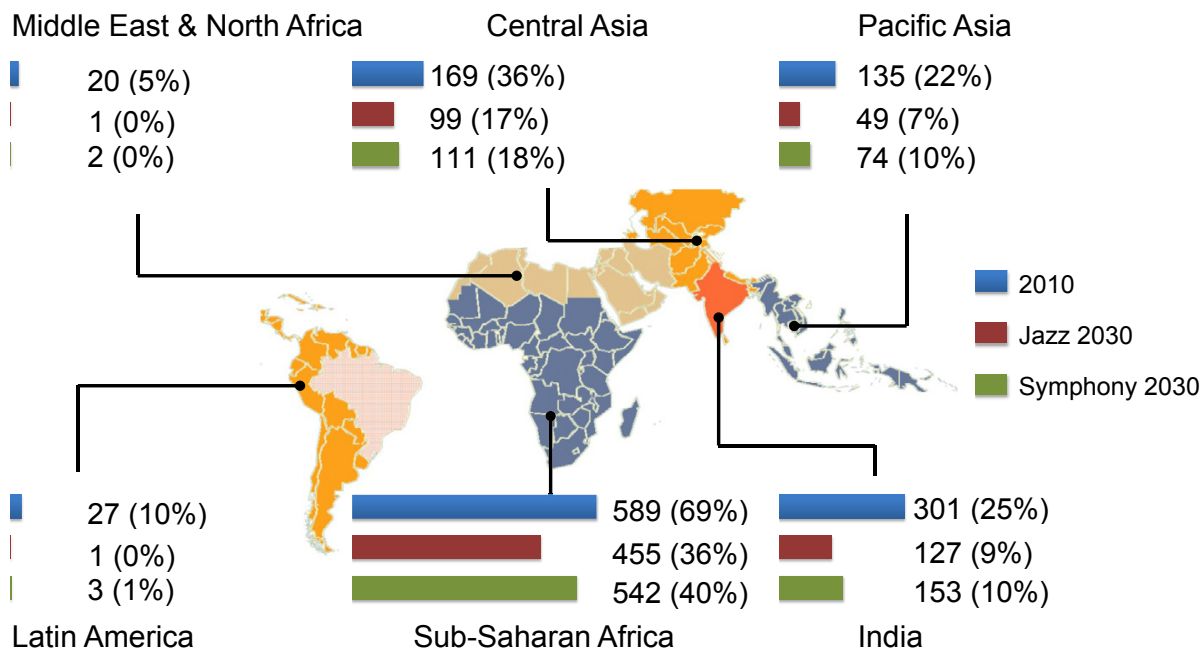

Fig. 11. Population without access to electricity by region, in millions and as $\%$ of total population.

period of 2011-2030. ${ }^{12}$ This is almost twice as high as the $\$ 9$ billion spent on electricity access in 2009 [2]. The investment for increasing the electricity access is higher in "Symphony" than in "Jazz" due to the capital intensive pathway of the power generation sector to achieve long-term environmental sustainability. Fig. 12 presents the annual investment to increase electricity access by region. In both scenarios, India accounts for more than $25 \%$ of the global investment for electricity access, reflecting the increasing need of the country to provide electricity access to its rural population. The above numbers imply that the average connection cost per capita is $\$ 370$ in "Jazz" and $\$ 460$ in "Symphony" for every person gaining electricity access during the period of 2011-2030.

\section{Achieving universal electricity access in "Jazz" and "Symphony"}

As shown in the previous section, the level of projected investments in the "Jazz" and "Symphony" scenarios is insufficient to achieve

\footnotetext{
12 To calculate the investment directed to increase electricity access we first estimate the need for electricity generation by matching the additional electricity demand from people gaining access over time to the existing residential electricity demand, total electricity generation and power capacity. The investments in generating access are then a straightforward calculation, based on the share of the total electricity generation capacity that corresponds to the increase in electricity access of the population. This is similar to the methodology applied by IEA [4].
}

universal electricity access by 2030. In this section we estimate the investment in power generation infrastructure required to meet the SE4All objective in the two WEC/PSI scenarios.

\subsection{Definition of the universal electricity access case}

In the universal electricity access case we assume that new policies and electrification programmes are implemented from 2015 that result in increasing the electrification rates to $100 \%$ of the world's population by $2030 .{ }^{13}$ In a first step, the annual additional number of people gaining access to electricity by region is estimated based on equation (1), in which we apply the adjustment factor $a_{r, t}$ in order to shift the electricity access curves towards the $100 \%$ electrification by 2030 . To assess the additional electricity demand (and hence the additional generating capacity) required to attain universal electricity access by 2030, we follow the same approach as IEA in Ref. [2]. We assume that once the initial basic consumption of electricity is achieved, the level of consumption rises gradually over time reaching the average regional consumption level after five years; this is a time dynamic assumption since the average regional consumption is calculated for every year over the projection period. This approach reflects the fact that the

\footnotetext{
13 In our analysis we abstain from identifying or suggesting policies that could increase the electricity access in developing regions.
} 
Jazz: $\$ 15.8$ billion

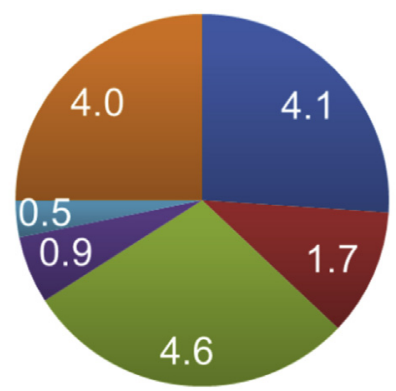

Pacific Asia
India
M. East \& N. Africa
Symphony: $\$ 17.9$ billion

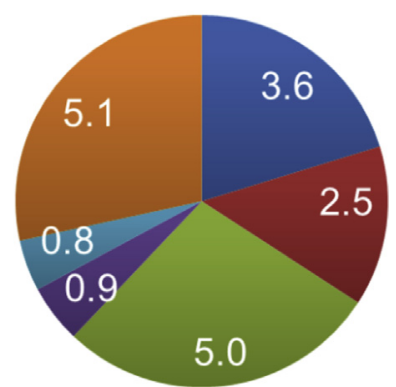

- Central Asia

- Latin America

- Sub-Saharan Africa
Fig. 12. Annual investment by region to increase electricity access, 2011-2030.

Table 9

Additional electricity consumption to achieve universal electricity access by region in 2030.

\begin{tabular}{|c|c|c|c|c|}
\hline & \multicolumn{2}{|c|}{ Jazz (in TWh) } & \multicolumn{2}{|c|}{ Symphony (in TWh) } \\
\hline & Base & Additional & Base & Additional \\
\hline Pacific Asia & 922 & $69(+7 \%)$ & 788 & $90(+11 \%)$ \\
\hline Central Asia & 301 & $59(+20 \%)$ & 302 & $66(+22 \%)$ \\
\hline India & 942 & $88(+9 \%)$ & 815 & $91(+11 \%)$ \\
\hline Latin America & 543 & $2(+0 \%)$ & 489 & $4(+1 \%)$ \\
\hline Middle East \& North Africa & 1109 & $3(+0 \%)$ & 1086 & $4(+0 \%)$ \\
\hline Sub-Saharan Africa & 387 & $285(+74 \%)$ & 369 & $329(+89 \%)$ \\
\hline Total in the regions above & 4203 & $507(+12 \%)$ & 3848 & $585(+15 \%)$ \\
\hline
\end{tabular}

eradication of energy poverty and the achievement of energy equity is a long term activity.

We set the initial level of annual electricity consumption to $120 \mathrm{kWh}$ per capita ${ }^{14}$ as suggested in Ref. [89]. However, different threshold levels are adopted in other analyses. IEA for example assumes an initial consumption of $250 \mathrm{kWh}$ per year for a rural household of five people and $500 \mathrm{kWh}$ per year for an urban household of the same size [2]. As another point of reference, according to the Government of India [90] the electricity consumption in 2009 was $96 \mathrm{kWh}$ per capita in rural areas and $288 \mathrm{kWh}$ per capita in urban areas. In Refs. [54] and [91] the minimum annual electricity consumption threshold is set to $420 \mathrm{kWh}$ per household gaining electricity access, which is enough to run some small appliances. This threshold translates into $84 \mathrm{kWh}$ per capita if we assume a household of five people. Nevertheless, in our study, the assumption of initial electricity consumption per capita is the subject of additional sensitivity analyses in a following sub-section.

We abstain from assessing a possible feedback of the increased electricity access to the rest of the economy, mainly due to the absence of unanimity across studies looking at the direction of causality between electricity consumption and economic growth (see for example Refs. [92-95]). However, some studies for developing countries (for example Refs. [96-98]) have shown that increased electrification rates of population lead to increased electricity supply, which in turn enhances productivity and enables the creation of new enterprises.

\footnotetext{
14 This level of consumption is equivalent to the use of a floor fan, a mobile telephone, an efficient refrigerator, a small TV and two bulbs for about $5 \mathrm{~h}$ per day in an average household of five people.
}

\subsection{Additional electricity demand needed to achieve universal electricity access}

We estimate that the total incremental final electricity consumption required to achieve universal electricity access by 2030 is 507 TWh in "Jazz" and 585 TWh in "Symphony" (Table 9). This corresponds to an increase in electricity demand by $12 \%$ in "Jazz" and $15 \%$ in "Symphony" compared to the base case. ${ }^{15}$ The average level of electricity consumption per capita across newly connected households over the period is $691 \mathrm{kWh}$ in "Jazz" and $660 \mathrm{kWh}$ in "Symphony". More than the half of the additional electricity demand takes place in Sub-Saharan Africa.

The definition of the universal electricity access case that we use in our analysis implies that although the starting consumption per capita is the same across regions, there is a regional difference depending on the average consumption per capita of each region. Hence, the effort to achieve energy equity is higher in those regions with high average electricity consumption per capita. For example the number of people in Pacific Asia without access to electricity is smaller than in Central Asia, but the additional electricity consumption in Pacific Asia required to eradicate energy poverty is higher, in order to bring the newlyconnected households to consumption levels of the alreadyconnected ones.

\subsection{Investments needed to achieve universal electricity access}

The GMM model quantifies the effort needed in terms of electricity generation capacity and T\&D grid expansion to achieve universal electricity access by 2030. It takes as input the updated useful energy demands from the econometric model corresponding to the increased levels of electricity consumption required to attain the target of universal electricity access. Subsequently the model finds the costoptimal configuration of the energy system to meet these new demands.

Fig. 13 presents the cumulative total investment in power generation capacity required to achieve universal electricity access by region and the breakdown of the incremental power generation capacity by fuel. In "Jazz" the power generation capacity increases by $133 \mathrm{GW}$ $(+11 \%$ from the base case), of which $76 \mathrm{GW}$ is fossil fuel based generation $(+15 \%), 28 \mathrm{GW}$ is hydropower $(+32 \%)$ and $21 \mathrm{GW}$ solar power $(+24 \%)$. In "Symphony" the additional investment in power generation capacity is $192 \mathrm{GW}(+13 \%$ from the base case), of which $54 \mathrm{GW}$ is fossil fuel based $(+13 \%), 46 \mathrm{GW}$ is hydropower $(+22 \%), 60 \mathrm{GW}$ is solar power $(+19 \%), 18 \mathrm{GW}$ is wind power $(+24 \%)$ and $7 \mathrm{GW}$ is nuclear $(+14 \%)$. These results suggest that renewables play a significant role in achieving universal electricity access. In both scenarios, more than half of the additional investment takes place in Sub-Saharan Africa. India alone accounts for one third of the incremental investment in developing Asia.

Fig. 14 presents the undiscounted annual investment expenditure required to achieve universal electricity access by region, as well as its breakdown terms of power generation capacity and electricity T\&D grid. The cumulative undiscounted investment expenditure over the period of 2011-2030 amounts to \$710 billion in "Jazz" and \$978 billion in "Symphony". This implies that the annual undiscounted outlays to achieve the SE4ALL objective are $\$ 36$ billion in "Jazz" and \$49 billion in "Symphony" over the period of 2011-2030. These amounts are equivalent to less than $4 \%$ of the global investments in power generation infrastructure attained in WEC/PSI scenarios [8]. The undiscounted connection costs per person gaining electricity access between 2011 and 2030 are on average of \$450 in "Jazz" and \$590 in

\footnotetext{
15 The base case of "Jazz" and "Symphony" in the text refers to the original WEC/PSI scenarios without the target of universal electricity access by 2030 .
} 

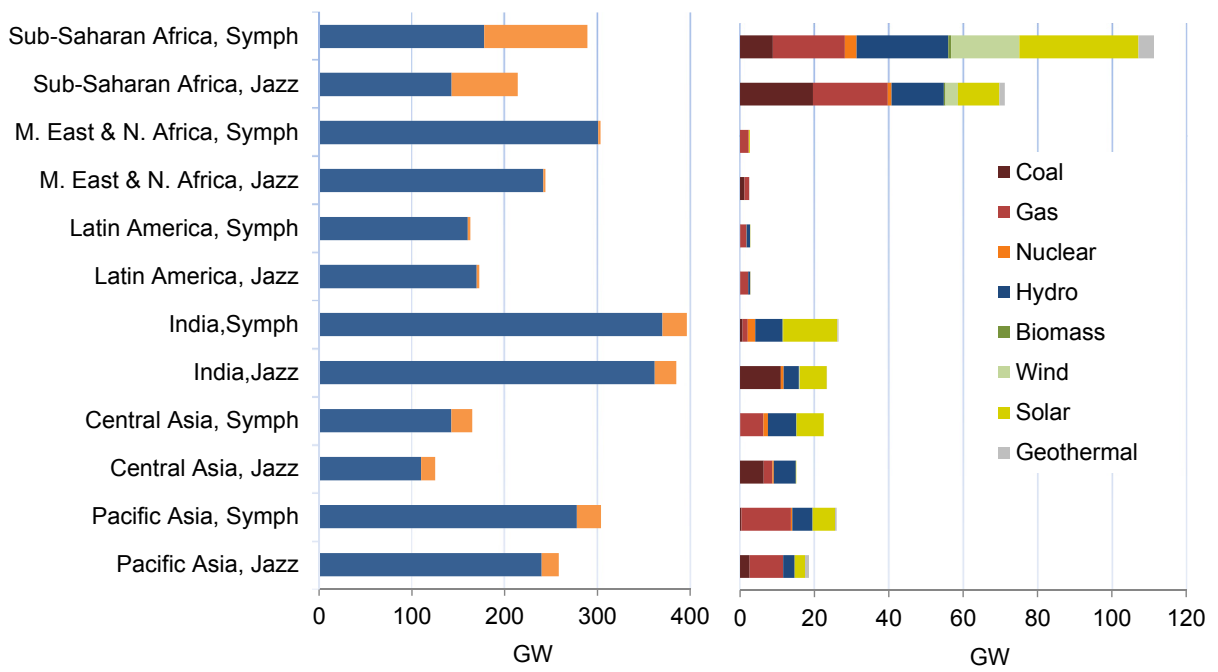

- Base case Additional in $100 \%$ access Breakdown of the additional investment

Fig. 13. Cumulative investment in electricity generation capacity in the universal electricity access case, 2011-2030.

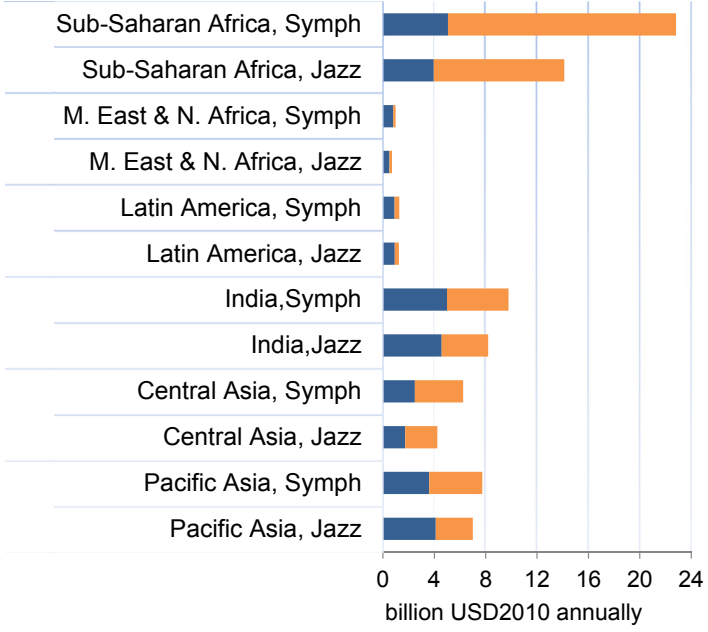

- Base case Additional in $100 \%$ access

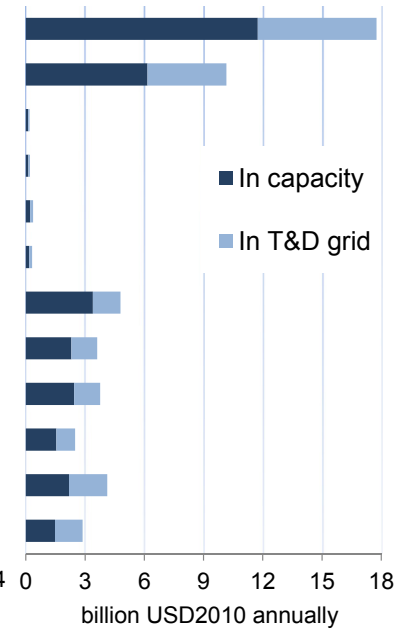

Breakdown of the additional investment

Fig. 14. Undiscounted annual investment expenditure in power generation infrastructure in the universal electricity access case, 2011-2030.

"Symphony". The connection costs per capita increase by $22 \%$ and $25 \%$ compared to the base case in "Jazz" and "Symphony" respectively, which is attributed to the higher effort required connecting remote and sparsely populated areas (Fig. 15). It should be noted that the connection costs are also influenced by the average level of the electricity consumption per capita, to which the consumption of the newly connected population convergences. Thus, Sub-Saharan Africa has the lowest connection costs per capita among all regions because of the very low average consumption per capita. On the other hand, Pacific Asia and Latin America display much higher connection costs per capita.

More than half of the additional investment expenditure occurs in Sub-Saharan Africa, with the region needing an annual investment of $\$ 14$ billion in "Jazz" and \$23 billion in "Symphony" to achieve universal electricity access by 2030 . Developing Asia requires $\$ 19$ billion in "Jazz" and \$24 billion in "Symphony" on annual basis over the period of 2011-2030 to meet the SE4ALL objective, the bulk of which is directed to India and Pacific Asia. Pacific Asia requires the largest additional investment per capita gaining electricity access among the developing regions, because of its high average electricity consumption per capita that increases the effort to eradicate energy poverty and to achieve energy equity in the region.

Table 10 presents the undiscounted cumulative investment expenditure in new power generation capacity by fuel that is required to achieve universal electricity access in developing regions. ${ }^{16}$ To raise this investment, a combination of different financing options is necessary depending on the electricity supply technology. For

\footnotetext{
16 The substantial investment in coal is due to the absence of stringent climate change targets and due to limits in the infrastructure expansion required to supply electricity from lower carbon intensive sources, e.g. gas pipelines required for gas turbine combine cycle plants and hydropower projects. In our analysis, in order to come up with plausible infrastructure expansion rates, we have taken into account the fact that the infrastructure to support the transition of the energy supply sector to low-carbon technologies is not currently fully in place in developing regions. This assessment was done in collaboration with the WEC members and the WEC scenario team.
} 


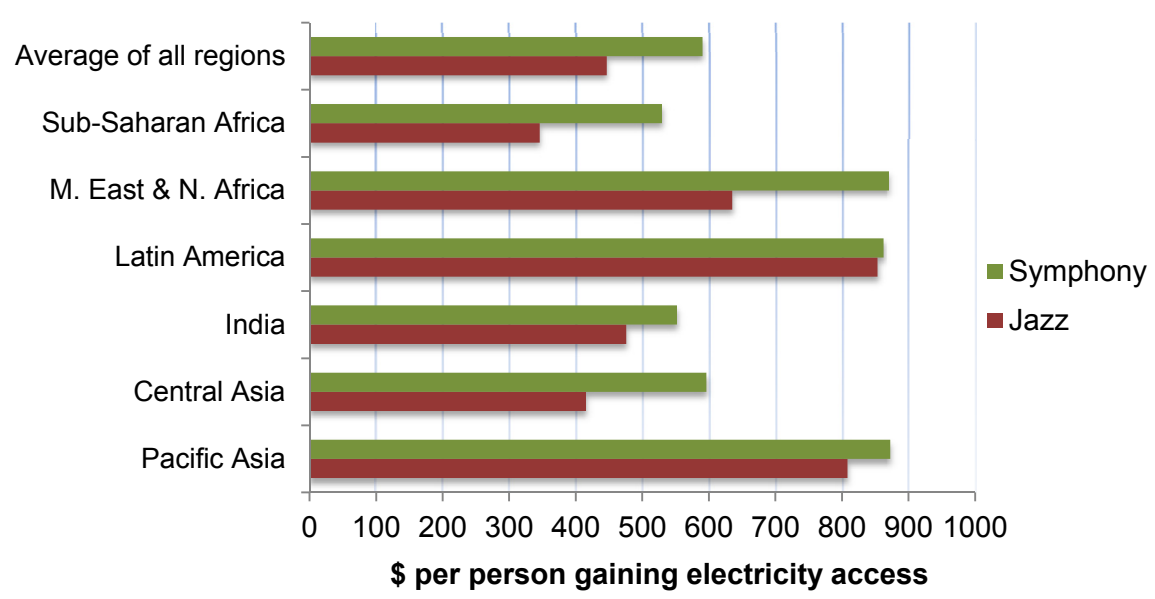

Fig. 15. Average undiscounted costs per newly capita in the universal electricity access case during the period 2011-2030.

Table 10

Cumulative investment expenditure in power generation capacity in billion USD2010 to achieve universal electricity access, 2011-2030.

\begin{tabular}{lcccc}
\hline & \multicolumn{2}{c}{ Total to achieve electricity access } & & \multicolumn{2}{l}{ Incremental from the base case } \\
\cline { 2 - 3 } \cline { 5 - 6 } & Jazz & Symphony & Jazz & Symphony \\
\hline Coal & 846 & 375 & 66 & 16 \\
Gas & 386 & 425 & 23 & 30 \\
Nuclear & 56 & 154 & 6 & 19 \\
Hydro & 346 & 776 & 83 & 139 \\
Biomass & 90 & 135 & 4 & 4 \\
Wind & 69 & 143 & 5 & 25 \\
Solar & 204 & 925 & 37 & 147 \\
Geothermal & 120 & 77 & 12 & 22 \\
Total & 2117 & 3010 & 236 & 402 \\
\hline
\end{tabular}

example, solar PV as an off-grid option is in general less financial attractive for the private sector. ${ }^{17}$ Possible solutions for raising the required funds can include: a) government programmes that improve the capacity of solar systems providers to finance end consumers (examples are found in Philippines [99] and Kenya [100]); b) local banks, government and concessional funds that support the provision of financial services to low-income population (examples of this approach include India Solar Programme [99] and some African countries [101]); c) sustainable solar marketing packages (SSMP) based on a service contract to install and maintain solar PV systems to public services sector and include exclusive rights to provide such services to private customers as well [102]; d) the development of solar home systems (SHS) that provide electricity to end users on a fee-for-service basis [103]; and e) solar portable light business models [104].

On the other hand, hydropower is a mature technology that can supply electricity at low costs, but hydropower projects can face significant financial and social risks. Successfully raising the required investment in hydropower depends on risk mitigation strategies addressing the high upfront capital expenditures and the lead times for planning, permitting and construction. Social risks include the relocation of people, which could start deep social disruption due to expropriations, asset condemnation and other losses. The mitigation of social risks needs to be addressed constantly throughout the entire project,

\footnotetext{
17 Investors compare the levelised cost of electricity from solar PV with the wholesale price and they also use a market-based weighted average cost of capital. Households instead compare the levelised cost of electricity from solar PV with the residential retail price, and they often use an interest rate based on their savings account.
}

and involves timely and continuous communications between developers and those affected, adequate compensation, support and long term contacts, and efforts to ensure that population relocation and land transformation is balanced by some direct benefits.

Fossil-based generation can increase electricity access in urban agglomerations that favour on-grid electrification options, but the grid expansion required is less profitable for the private sector. ${ }^{18}$ Financing schemes to raise investments in on-grid electrification could consider: a) public-private partnerships through which a local utility extends the grid to provide access in an agreed area by including generation and transmission together [104]; b) sourcing loans from the private sector to supplement internal financing of state-owned utilities; and c) partial risk guarantees, targeted government subsidies to low income households, equity investments, cross-subsidisation, etc.

The role of nuclear power in the universal electricity access case is constrained by issues related to technical capacity and safety, grid interface, legal and regulatory infrastructure and high upfront investment, especially in developing countries that start from green fields. A promising direction for nuclear development might be to downsize reactors from gigawatt scale to less-complex smaller units. Small modular reactor (SMR) technology could be a part of the solution [31].

The above discussion regarding the financing options of the different technologies suggests that the governments alone cannot fully finance the universal electricity access case. The participation of the private sector in the investment needs for the universal electricity access case depends on the ability of the investors to charge electricity tariffs that could return a reasonable profit. To this extent the biggest challenge is the electrification of low-income households, which can be financed from government budgets, multilateral and bilateral guarantees, concessional loans and grants through development banks (e.g. the World Bank, the African Development Bank) [105].

\subsection{Implications of universal electricity access in primary energy supply and $\mathrm{CO}_{2}$ emissions}

Achieving universal electricity access is projected to increase the primary energy consumption in developing regions by $4.2 \mathrm{EJ}$ in "Jazz" $(+1.8 \%$ from the base case) and by 3.8 EJ in "Symphony" $(+1.9 \%)$ in

\footnotetext{
18 Electricity transmission infrastructure needs high upfront investment in view of future electricity demand growth. It requires a high level of electricity consumption per capita, strong growth of retail electricity prices and adequately high transmission tariffs in order for the investment to be attractive to private investors. These conditions are hard to meet in developing regions with low incomes and low levels of electricity consumption per capita.
} 
EJ

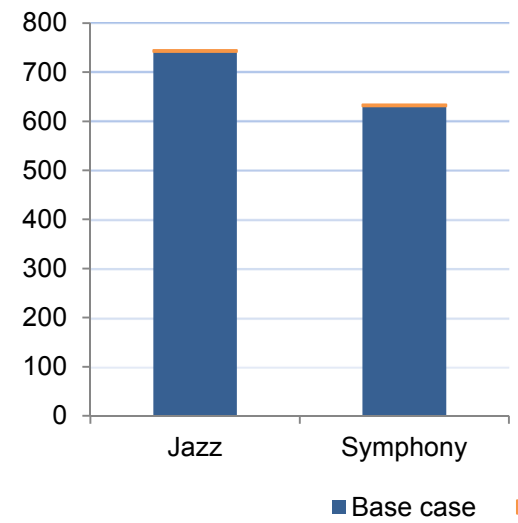

$\mathrm{Gt} \mathrm{CO}_{2}$

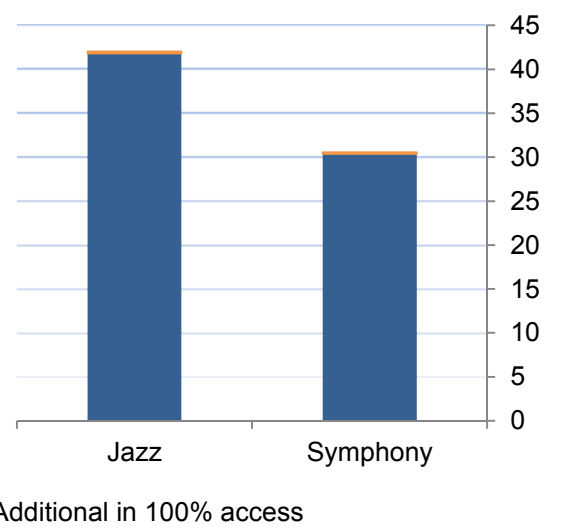

Fig. 16. Total global primary energy supply (left) and $\mathrm{CO}_{2}$ emissions in 2030 (right) in the base and universal electricity access cases of the two WEC/PSI scenarios.

2030. This translates to a global increase in primary energy supply of $0.6 \%$ in "Jazz" and $0.7 \%$ in "Symphony" in 2030 (Fig. 16). These small impacts on primary energy demand can be explained by the low level of energy per capita consumed by the people provided with electricity access. The intra-scenario comparison shows that "Symphony" requires $13 \%$ lower primary energy consumption in developing regions than "Jazz" (205 EJ versus 234 EJ).

The energy-related $\mathrm{CO}_{2}$ emissions in the universal electricity access case in developing regions are $12.3 \mathrm{Gt}$ in "Jazz" $(+2.1 \%$ from the base case or $+250 \mathrm{Mt})$ and $9.3 \mathrm{Gt}$ in "Symphony" $(+1.2 \%$ from the base case or $+110 \mathrm{Mt}$ ) in 2030 (Fig. 16). This translates to a global increase in energy-related $\mathrm{CO}_{2}$ emissions of around $0.5 \%$ in "Jazz" and $0.7 \%$ in "Symphony" in 2030. The small increase in emissions is because of the high shares of renewable options implemented. However, the pathway to achieve universal electricity access in "Jazz" is based on investments in fossil fuel based generation with long lifetimes that result in $25 \%$ higher cumulative $\mathrm{CO}_{2}$ emissions than in "Symphony" in developing regions. ${ }^{19}$ However, the diversity of factors involved implies that the total impact on greenhouse gas emissions from achieving universal electricity access and using modern cooking and lighting facilities needs to be treated with caution, especially as these factors are not fully captured by the present study. It is accepted in literature that advanced stoves and greater conversion efficiencies result in a reduction in $\mathrm{CO}_{2}$ emissions and thereby can lower our projection [2]. This might be the case even if access is provided entirely from fossil energy resources, because the transition to such fuels displaces large quantities of traditional biomass that is associated with significant emissions of non- $\mathrm{CO}_{2}$ Kyoto gases (e.g. $\mathrm{CH}_{4}$ and $\mathrm{N}_{2} \mathrm{O}$ ) [54]. For comparison IEA estimates that achieving universal electricity access by 2030 would raise $\mathrm{CO}_{2}$ emissions by $0.7 \%$ as compared to their "New Policies" scenario [2], while [54] estimates an increase of GHG emissions of about $2-4 \%$ above the baseline in 2030. In Ref. [49], it is calculated that the additional $\mathrm{CO}_{2}$ emissions due to energy poverty eradication are in the range of $44-183 \mathrm{Gt} \mathrm{CO}_{2}$ over the 21 st century with the maximum warming contribution of increased energy access estimated to $0.13^{\circ} \mathrm{C} .{ }^{20}$

\footnotetext{
19 As it is mentioned in Ref. [8], the "Jazz" scenario follows a trajectory consistent with a long term atmospheric concentration between 590 and 710 ppm $\mathrm{CO}_{2}$-eq, which corresponds to a more than $66 \%$ probability of a warming of $4^{\circ} \mathrm{C}$ according to [106], while "Symphony" is on track for $490-535$ ppm $\mathrm{CO}_{2}$-eq that corresponds to a probability of $33-50 \%$ of meeting the $2{ }^{\circ} \mathrm{C}$ target [106].

20 This evidence is also supported by looking at retrospective analyses which show that in India, for example, increased electricity access has contributed $3-4 \%$ of the national emissions growth over the past 30 years [107].
}

\subsection{Sensitivity analyses}

In order to further enhance the analysis and assess the robustness of the results discussed in the previous sections, we perform a number of sensitivity analyses regarding: a) the initial level of electricity consumption per capita for the newly-connected population; b) the electricity T\&D grid expansion cost; and c) the GDP and population assumptions.

\subsubsection{Sensitivity on initial level of electricity consumption per capita}

The initial electricity consumption for newly-connected population constitutes a key assumption in the model that affects the level of investment required to attain universal electricity access. Different studies consider different levels above which access to electricity is assumed to be established. Therefore, we perform a sensitivity analysis regarding the annual starting electricity consumption for newlyconnected population in the range of $60-180 \mathrm{kWh}$ per capita for both scenarios. This range includes the initial electricity consumption levels reported in the majority of the studies in literature.

Fig. 17 presents the annual undiscounted investment in power generation infrastructure required to achieve universal electricity access by 2030 . The investment in the "Jazz" scenario ranges from $\$ 33$ billion ( $-6.1 \%$ compared to the base case of $120 \mathrm{kWh}$ per capita) to $\$ 37$ billion annually $(+5.1 \%$ from the base case of $120 \mathrm{kWh}$ per capita). "Symphony" displays lower volatility in initial consumption levels than "Jazz", with the annual investment of the scenario ranging from $\$ 46$ billion $(-5.3 \%$ compared to $120 \mathrm{kWh}$ per capita case) to $\$ 51$ billion $(+3.9 \%$ compared to $120 \mathrm{kWh}$ per capita case). This is attributable to the more capital intensive pathway of "Symphony" because of the emphasis on sustainability. In "Jazz", the capital demanding investment options are considered last in the merit order of supply due to the focus in this scenario on low-cost energy; this increases the sensitivity of "Jazz" to higher initial electricity consumption levels.

\subsubsection{Sensitivity on electricity T\&D grid expansion costs}

The electricity T\&D grid expansion costs assumed in the study depend on the population density and urbanisation levels of each region and are shown in Table 7 . In the universal electricity access case the investments in the T\&D grid represent about $43 \%$ of the total annual expenditure in power generation infrastructure in "Jazz" and $37 \%$ in "Symphony". In order to assess the sensitivity of the annual investment expenditures with respect to the electricity grid costs, we perform additional analyses by varying these costs by $\pm 50 \%, \pm 25 \%$ and $\pm 10 \%$ from the base case. This type of analysis also provides insights about 

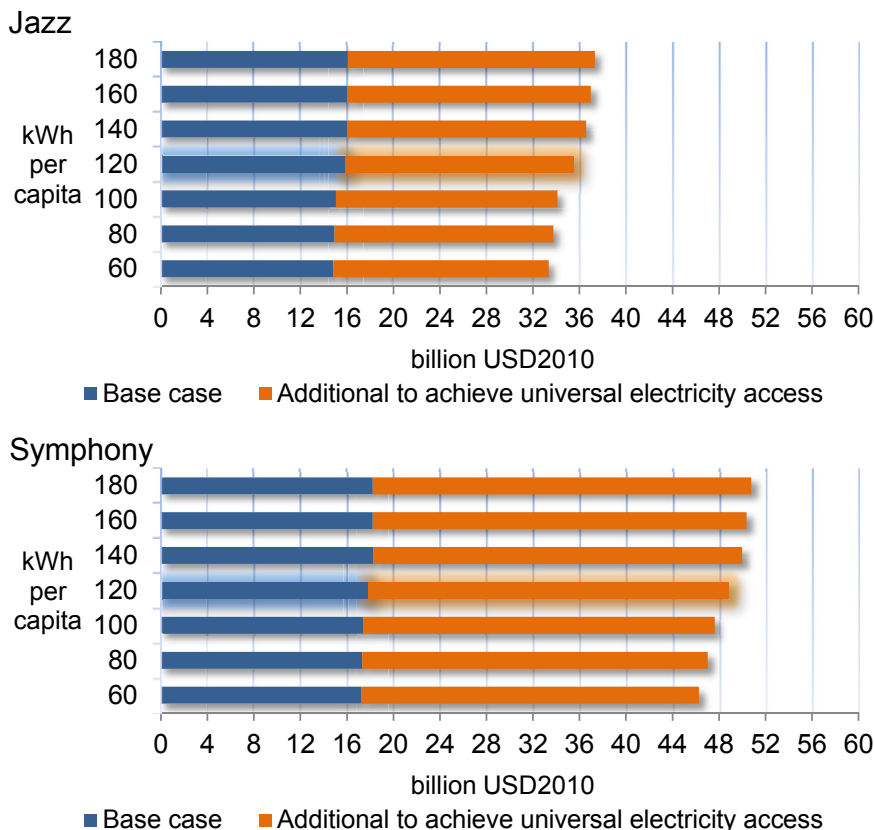

Fig. 17. Annual investment to achieve universal electricity access in billion US\$ for different levels of initial electricity consumption compared to the base case (highlighted) of $120 \mathrm{kWh}$ per capita and year, 2011-2030.

the trade-off between decentralised generation and electricity grid expansion. High T\&D grid expansion costs can favour the adoption of decentralised options to supply electricity in rural areas, but at the same time these options have significantly higher specific investment costs compared to centralised technologies due to differing economies of scale.

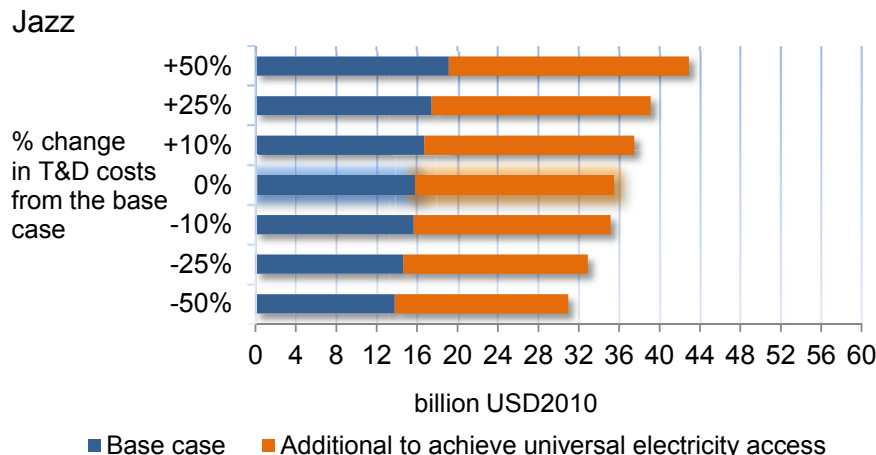

Symphony

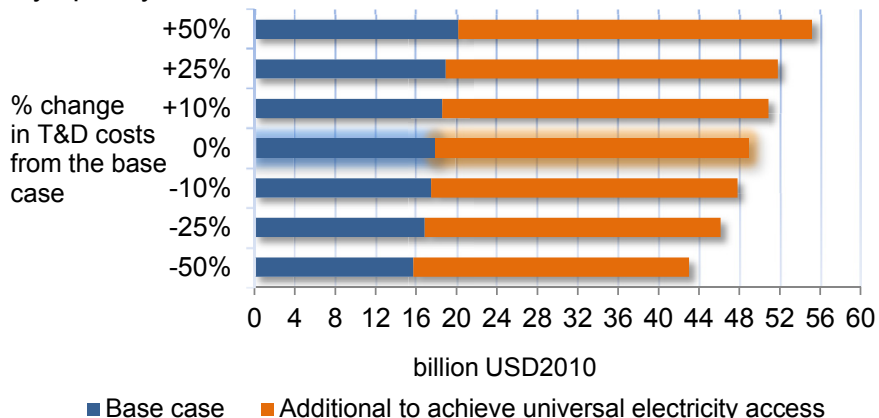

Fig. 18. Annual investment to achieve universal electricity access in billion US\$ for different levels of electricity T\&D grid expansion costs, 2011-2030.

\begin{tabular}{|c|c|c|c|c|}
\hline Variant name & $\begin{array}{l}\text { Policies } \\
\text { from }\end{array}$ & $\begin{array}{l}\text { Assumption(s) } \\
\text { modified }\end{array}$ & $\begin{array}{l}\text { Total } \\
\text { Population } \\
\text { (millions) }\end{array}$ & $\begin{array}{l}\text { Average } \\
\text { income } \\
(\$ 2010)\end{array}$ \\
\hline Jazz & Jazz & WECIPSI Jazz scenario & 4897 & 5704 \\
\hline $\begin{array}{l}\text { Jazz (GDP } \\
\text { from Symph) }\end{array}$ & Jazz & $\begin{array}{l}\text { GDP growth from } \\
\text { Symphony }\end{array}$ & 4897 & 5086 \\
\hline $\begin{array}{l}\text { Jazz (POP } \\
\text { from Symph) }\end{array}$ & Jazz & $\begin{array}{l}\text { Population growth from } \\
\text { Symphony }\end{array}$ & 5066 & 5514 \\
\hline $\begin{array}{l}\text { Jazz (POP\&GDP } \\
\text { from Symph) }\end{array}$ & Jazz & $\begin{array}{l}\text { GDP \& population growth } \\
\text { from Symphony }\end{array}$ & 5066 & 4917 \\
\hline Symphony & Symphony & $\begin{array}{l}\text { WECIPSI Symphony } \\
\text { scenario }\end{array}$ & 5066 & 4917 \\
\hline $\begin{array}{l}\text { Symph (GDP } \\
\text { from Jazz) }\end{array}$ & Symphony & GDP growth from Jazz & 5066 & 5514 \\
\hline $\begin{array}{l}\text { Symph (POP } \\
\text { from Jazz) }\end{array}$ & Symphony & $\begin{array}{l}\text { Population growth } \\
\text { from Jazz }\end{array}$ & 4897 & 5086 \\
\hline $\begin{array}{l}\text { Symph (POP\&GDP } \\
\text { from Jazz) }\end{array}$ & Symphony & $\begin{array}{l}\text { GDP \& population growth } \\
\text { from Jazz }\end{array}$ & 4897 & 5704 \\
\hline
\end{tabular}

By changing the T\&D costs by $\pm 50 \%$ we find that in "Jazz" the annual investment in power generation infrastructure ranges from $\$ 31$ billion $(-13 \%$ from the base case) to $\$ 43$ billion $(+21 \%$ from the base case) over the period 2011-2030, while for "Symphony" the obtained interval is from $\$ 43$ billion ( $-12 \%$ from the base case) to $\$ 55$ billion $(+13 \%$ from the base case) for the same period (see Fig. 18). This implies that a significant part of the reduction or the increase in the T\&D electricity grid expansion costs is traded-off with reduced or increased decentralised generation respectively. The investment expenditures in the decentralised generation capacity in "Jazz" are between $16.6 \%$ (in the $-50 \%$ case) to $22.4 \%$ (in the $+50 \%$ case) of the total investments in power generation capacity in developing regions. In "Symphony", the investment expenditures in decentralised generation capacity are between $32.4 \%$ (in the $-50 \%$ case) to $36.4 \%$ (in the $+50 \%$ case) of the total investments in power generation capacity.

Compared to the base case more than half of the additional investment in decentralised generation in the variants with higher T\&D electricity grid costs is directed to solar photovoltaics. The remaining investments are in small scale gas CHP plants (around $30-40 \%$ of the investment in decentralised generation in "Jazz", but less than $15 \%$ in "Symphony"), biomass thermal/gasification units (around 6\% of the investment in decentralised generation in "Jazz" and about $20 \%$ in "Symphony") and small scale run-of-river hydro projects (around 2-3\% of the investment in decentralised generation in "Jazz" and less than $15 \%$ in "Symphony").

The analysis shows that the "Jazz" scenario exhibits higher sensitivity to electricity grid expansion costs than "Symphony". This is attributable to the centralised model of electricity generation that is followed in this scenario, which aims at providing low-cost energy through large economies of scale. On the other hand, the "Symphony" scenario already in the base case displays doubled shares of decentralised generation compared to "Jazz". Therefore it is less sensitive to the changes in T\&D electricity grid expansion costs assumptions.

\subsubsection{Sensitivity on economic and demographic assumptions}

Economic and demographic developments affect investments in attaining universal electricity access: a) by influencing the number of people that do not have access to electricity in the base case; and b) by influencing the level to which the average electricity consumption per capita for the newly-connected population converges (after 5 years of their initial consumption), in order to eradicate the energy poverty. 


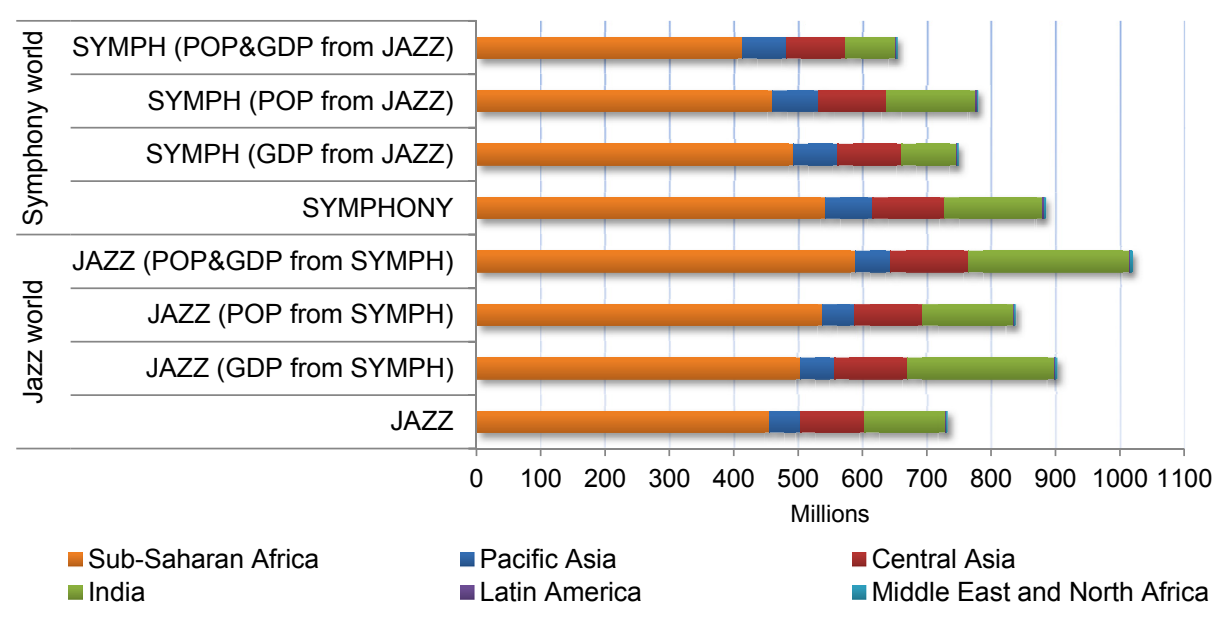

Fig. 19. Population without access to electricity in "Jazz" and "Symphony" and in their variants, 2030.

The different sensitivity analyses on GDP and population assumptions of the two scenarios are shown in Table 11.

Fig. 19 compares the population without electricity access across all scenarios and variants in 2030. In a "Jazz-like" world ${ }^{21}$ the number of people without access to electricity in 2030 ranges from 733 million in "Jazz" to 1020 million in "Jazz (POP\&GDP from Symph)". In a "Symphony-like" world ${ }^{22}$ the number of people without access to electricity in 2030 ranges from 654 million in "Symph (POP\&GDP from Jazz)" to 885 million in "Symphony". Looking at the population electrification rates, in a "Jazz-like" world they range from $80 \%$ to $85 \%$, while in a "Symphony-like" world they range from $80 \%$ to $87 \%$. These results suggest that for the same level of population and economic growth a "Symphony-like" world achieves higher population electrification rates than a "Jazz-like" world.

There are a number of contributing factors that can explain why "Symphony" performs better than "Jazz" for the same level of average income per capita. The electricity access in "Jazz" is linked with the ability and/or willingness of consumers to pay for connection and operating costs in a liberalised market without energy subsidies. This implies that the "Jazz" scenario is imbalanced with respect to electricity access between urban and rural areas, since utilities can supply on-grid electricity at low costs to urban areas, while they are reluctant to serve rural areas. Moreover the off-grid generation is not subsidised in this scenario. On the other hand, electricity access in "Symphony" is linked with the capacity of governments to invest or support off-grid distributed generation to combat energy poverty in rural areas. This implies that "Symphony" is more balanced with respect to electricity access between urban and rural areas than "Jazz". In addition, in the "Symphony" scenario there are also policies for supporting efficiency and reducing the $\mathrm{CO}_{2}$ emissions in the demand sectors. These policies increase the share of electricity in final energy consumption and consequently the investments in power generation infrastructure and electricity access.

Fig. 20 presents the electricity consumption in the residential sector and the cumulative undiscounted annual investment expenditure in power infrastructure required to achieve universal electricity access in all variants under consideration. In a "Jazz-like" world the annual outlays range from $\$ 34$ billion to $\$ 38$ billion, while in a "Symphony-like" world they are between $\$ 46$ billion and $\$ 50$ billion.

\footnotetext{
21 Refers to the "Jazz" scenario and all variants with policies from "Jazz".

22 Refers to the "Symphony" scenario and all variants with policies from "Symphony".
}

\subsection{Comparison with other studies}

In the WEC/PSI "Jazz" and "Symphony" scenarios, we estimate that 733 million and 885 million people lack access to electricity in 2030 respectively. In order to achieve the SE4ALL target, the required annual undiscounted investments in power generation infrastructure is $\$ 36$ billion in "Jazz" and $\$ 49$ billion in "Symphony" over the period of 2011-2030. The universal electricity access case increases the primary energy supply from $1.8 \%$ to $1.9 \%$ from the base case in both scenarios in 2030 , while the $\mathrm{CO}_{2}$ emissions increase by $1.2 \%$ in "Jazz" and $2.1 \%$ in "Symphony" in the same period. In addition, the sensitivity analyses suggest that the annual investment expenditures can be as low as $\$ 31$ billion and as high as $\$ 55$ billion over the period of 2011-2030, depending on the underlying assumptions of initial electricity consumption levels, electricity T\&D grid expansion costs, economic developments and population growth.

These findings are generally in line with results from similar studies. IEA estimates that 1036 million people lack access to electricity by 2030 and that an annual investment of $\$ 45$ billion over the period of 2011-2030 is required to achieve universal electricity access by then [2]. It is also estimated that the universal electricity access case increases the primary energy supply by $1.1 \%$ and the additional impact on $\mathrm{CO}_{2}$ emissions is $+0.7 \%$ in 2030 compared to IEA's base case of "New Policies" scenario. In Ref. [3] IEA updated these numbers to 991 million people without access to electricity in 2030 and to $\$ 49$ in billion annual investment expenditure over the period of 2011-2030 in order to achieve universal electricity access by 2030. In Ref. [53], it is estimated that without additional policies to increase electrification, between 795 million and 822 million people living in rural areas in Sub-Saharan Africa and South and Pacific Asia will remain without access to electricity by 2030 and that $\$ 36$ billion to $\$ 41$ billion will need to be spent annually until 2030 to ensure universal access to clean cooking fuels and electricity by 2030. In Ref. [54] it is estimated that without policies to accelerate electrification 600 million to 850 million people in rural Sub-Saharan Africa and South and Pacific Asia could remain without electricity by 2030 . It also suggests that around $\$ 65$ billion to $\$ 86$ billion ${ }^{23}$ would be required annually worldwide to achieve universal access to clean cooking fuels and electricity by 2030 . This corresponds to approximately $3 \%-4 \%$ of global investments in electricity generation

\footnotetext{
23 The costs are expressed in real USD of 2005. By applying a GDP deflator of approx. 1 . 11 to change the base year from 2005 to 2010 , the resulting annual investments is $\$ 72$ to $\$ 95$ billion of USD2010 over the period 2011-30.
} 


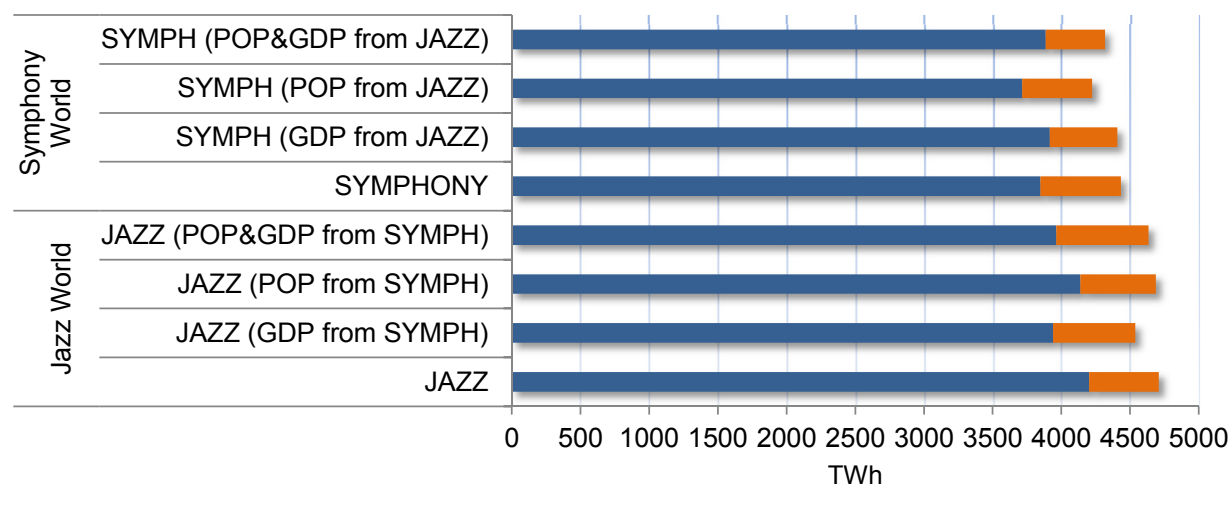

Base case $\quad$ Additional to achieve universal access

(a)

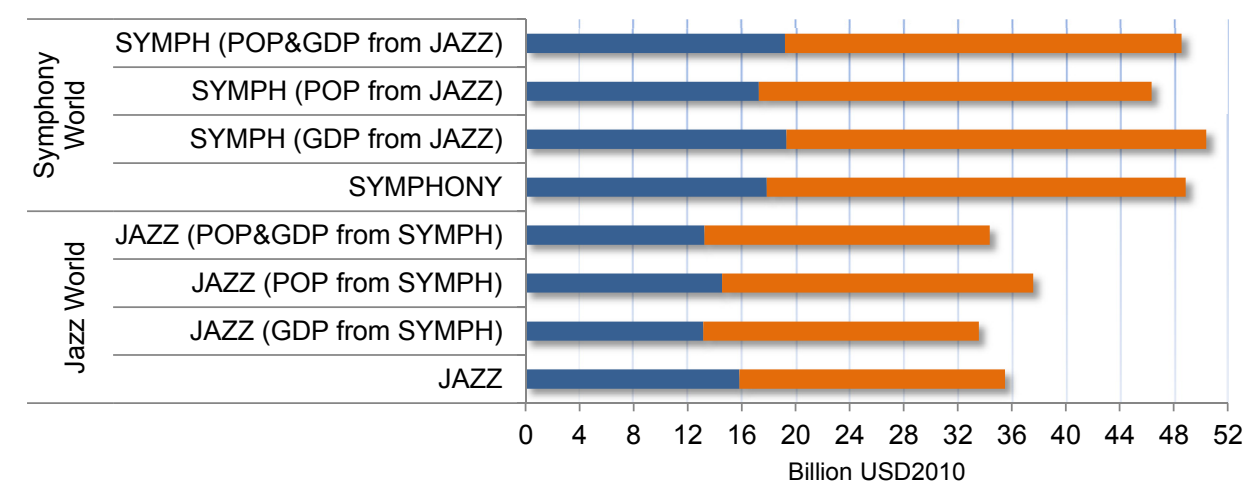

Base case investment $\quad$ Incremental investment to achieve universal access

(b)

Fig. 20. (a) Electricity consumption in TWh and (b) Annual investment to achieve universal electricity access in billion US\$, 2011-2030.

and transmission and distribution infrastructure. The same study estimates that universal modern energy access increases greenhouse gases emissions by about $2 \%-4 \%$ over the baseline in 2030 . In Ref. [59] it is estimated that around 650 million people will lack access to electricity in rural areas by 2030 . Achieving universal electricity access by then would require $\$ 24$ billion to $\$ 43$ billion, ${ }^{24}$ which corresponds to a range of $3.6 \%-6.5 \%$ of global investments in the power sector in the period of 2011-2030.

In Ref. [108] a compilation of studies assessing the cost of universal electricity access by 2030 is presented. The study finds that the annual investment expenditure in power generation infrastructure ranges from $\$ 35$ billion to $\$ 55$ billion over the period of 2011-2030.

The findings of the abovementioned studies indicate the robustness of our results and constitute a positive outcome for the methodology that we apply. They also indicate a general consensus that despite the different methodologies applied in studies and the different policy scenarios assessed in them, the annual investment outlays in power generating infrastructure required to achieve universal electricity access range between $\$ 30$ billion to $\$ 60$ billion USD2010 over the period of 2011-2030.

\footnotetext{
24 The costs are expressed in real USD of 2005. By applying a GDP deflator of approx. 1. 1 to change the base year from 2005 to 2010 , the resulted annual investments range from $\$ 26$ to $\$ 48$ billion over the period 2011-2030.
}

\section{Conclusions}

Modern energy services are crucial to economic and social development, yet this is out of reach of the people most in need. The latest statistics from IEA and the World Bank show that the population without access to electricity has increased in recent years as natural population growth outpaces the number of new electricity connections [4]. This imposes significant challenges in meeting the UN "Sustainable Energy For All - SE4ALL" objective of achieving universal electricity access by 2030 .

In order to provide insights regarding population electrification rates in 2030 and the additional investment effort in power generation infrastructure required to meet the SE4ALL objective, we analyse two explorative scenarios developed by the World Energy Council and the Paul Scherrer Institute that describe alternative configurations of the economy, population and energy policies. We find that in the absence of new policies 733 million to 885 million people lack electricity access by 2030 in the two WEC/PSI scenarios, which corresponds to a reduction of about 400-500 million people compared to 1285 million in 2012. This is equivalent to an increase in the population electrification rate in developing regions from $67 \%$ in 2012 to $85 \%$ in "Jazz" and $83 \%$ in "Symphony" by 2030. Poverty, urbanisation and government effectiveness constitute key socio-economic drivers that affect population electrification rates. In our projections the population without access to electricity becomes increasingly concentrated in Sub-Saharan Africa due to factors relating to demographic trends, the current state of 
electricity infrastructure, the nature and extent of expected flows of investments to different parts of the power sector and the large size of many African countries.

In order to achieve universal electricity access we estimate that the total annual investment expenditure in power generation infrastructure is on the order of 36-49 billion dollars depending on energy policies and developments in the economy and demography in the two WEC/PSI scenarios. The size of this investment corresponds to less than $4 \%$ of the global investment in power generation infrastructure over the same period in the two WEC/PSI scenarios. A significant share of the investment required to achieve universal electricity access is directed towards renewable options: solar and hydropower play an important role in providing electricity at low costs. Fossil fuel based generation is considered to be a near-term solution and nuclear power is constrained by issues related to high capital costs, safety, legal and regulatory investments.

The participation of the private sector is important in order to raise the necessary funds to achieve universal electricity access. The governments of developing countries not only need to address the design and implementation of suitable policies, but also create an investment climate to mobilise domestic and foreign capital and innovation. As political momentum is building and energy access is becoming a political priority, governments also need to start adopting staged energy access targets and allocating funds to achieve them.

In the WEC/PSI scenarios the universal electricity access case increases the global primary energy demand by $0.6-0.7 \%$ compared to the base case. This is because newly-connected people exhibit low levels of energy consumption per capita. The impact of universal electricity access on the increase of cumulative global $\mathrm{CO}_{2}$ emissions is $0.3 \%$ compared to the base case over the period of 2011-2030. This is mainly because of the relatively high shares of renewables options (solar, hydro, etc.) that are chosen in order to achieve universal electricity access. However, if the global electricity access agenda is not paired more robustly with the climate agenda, the energy poor will be left behind. Empirical evidence from Bangladesh, Bolivia and Rwanda shows capable manpower in the energy access space to be extremely limited. Meaningful and sustainable approaches to energy access remain largely unfamiliar to most actors in the energy sector and the only way to deliver on them is to radically and urgently ramp-up broad-based capacity building on decentralised approaches to energy service provision amongst practitioners, policymakers and the finance community [109].

In order to gain more insights regarding the financial effort required to meet universal electricity access until 2030 we also perform a series of sensitivity analyses on key assumptions regarding: i) the initial electricity consumption levels for the newly connected population; ii) the electricity T\&D grid expansion costs; and iii) the main economic and demographic assumptions of the two scenarios. The sensitivity analyses suggest that the investment cost in power generation infrastructure required for the universal electricity access case can range from $\$ 31$ billion to $\$ 55$ billion. The investment expenditures in increasing electricity access are more sensitive to the electricity T\&D grid expansion costs than to the initial electricity levels of consumption, because the grid cost significantly affects the cost of delivered electricity and hence the choice of technologies that supply remote rural areas. In addition, for the same level of income the electrification rates of the population are likely to be higher when policies supporting efficiency and environmental sustainability are in place. In general, the range of investment expenditure required to achieve universal electricity access in the current analysis is in-line with estimates reported in similar studies, such as those from IEA, IIASA, RIVM and from others. This result constitutes a positive outcome for the methodology we applied and for the robustness of our analysis.

The two scenarios analysed in this paper can facilitate the exploration of different strategies and policy mixes that balance low-cost energy and environmental sustainability in order to meet the goals of the SE4ALL objective. The results obtained from this work help in identifying the major opportunities and challenges in achieving universal electricity access in a global context of unprecedented uncertainty regarding international energy prices and patterns of energy trade, global competition for investment capital, technical progress and international interactions in environmental aspects.

Beyond these broad findings, it is of course critical to emphasise that the developing Asia, Latin America and Sub-Saharan Africa are very diverse regions with different sub-challenges and respective solutions. This heterogeneity is not directly addressed in our analysis. To tackle this we aim at enhancing the regional detail of the two models and performing regional deep-dives in collaboration with WEC. This can also include a more complete representation of the current infrastructure networks (for example length and quality of the electricity grid lines). Additional sensitivity analyses of key scenario drivers can further enhance the findings of this study as well.

Finally, the econometric model that we apply in our analysis for estimating the population with access to electricity takes into account only few of the factors that have been identified as statistically significant in the relevant literature (e.g. in Refs. [43,50,57,59]). This is mainly because this model is coupled with a bottom-up model, like GMM, which does not consider variables at macro-economic level. A coupling with a top-down general equilibrium model, or even better with a hybrid top-down/bottom-up framework, would require an extension of the econometric model to include additional variables such as: human development index, Gini index, net aid inflows, consumer expenditure to energy and goods, fuel prices, fuel taxes, fuel subsidies, fuel exports and imports, share of industry and services in GDP, levels of household consumption (in monetary units), external balances of good and services, public sector consumption relative to GDP, population access to education, etc. Such an expansion can provide additional insights and capture better the complexity of the problem of increasing electricity access in developing regions. Therefore, it can substantially improve the findings of this study and their quality.

\section{Acknowledgments}

The research was supported financially by the Swiss Federal Office of Energy (Bundesamt für Energie - BFE) and the Swiss Energy Council (Schweizerischer Energierat). The authors would like also to thank the members of the scenario study group of the World Energy Council for their useful inputs as well as the anonymous reviewers for their constructive suggestions and comments in improving the original manuscript.

\section{References}

[1] M. Kanagawa, T. Nakata, Assessment of access to electricity and the socioeconomic impacts in rural areas of developing countries, Energy Policy 36 (2008) 2016-2029. http://dx.doi.org/10.1016/j.enpol.2008.01.041.

[2] International Energy Agency (IEA), Energy for All: Financing Access for the Poor, Special Excerpt of the World Energy Outlook 2011, OECD/IEA, Paris, 2011.

[3] International Energy Agency (IEA), World Energy Outlook 2012, OECD/IEA, Paris, 2012.

[4] International Energy Agency (IEA), World Energy Outlook 2014, OECD/IEA, Paris, 2014

[5] S.G. Banerjee, M. Bhatia, G.E. Azuela, I.S. Jaques, P.E. Ashok, I. Bushueva, N. Angelou, J.G. Inon, Global Tracking Framework. Vol. 3 of Global Tracking Framework, Sustainable Energy for All, The World Bank, Washington D.C, 2013 available online at: http://documents.worldbank.org/curated/en/2013/05/ 17765643/global-tracking-framework-vol-3-3-main-report (Accessed 08.09.14).

[6] C.E. Casillas, D.M. Kammen, The energy-poverty-climate nexus, Science 330 (2010) 1181-1182. http://dx.doi.org/10.1126/science.1197412.

[7] World Energy Council (WEC), World energy trilemma, WEC, available online at: http://www.worldenergy.org/wp-content/uploads/2013/11/2013-Time-to-getreal-the-agenda-for-change.pdf, 2013 (Accessed 08.09.14).

[8] C. Frei, H. Turton, M. Densing, E. Panos, K. Volkart, et al., World Energy Scenarios - Composing Energy Futures to 2050, World Energy Council, London, 2013. 
Available at: http://www.worldenergy.org/publications/2013/world-energyscenarios-composing-energy-futures-to-2050/ (Accessed 30.11.14).

[9] S. Bhattacharyya, Financing energy access and off-grid electrification: a review of status, options and challenges, Renew. Sustain Energy Rev. 20 (2013) 462-472. http://dx.doi.org/10.1016/j.rser.2012.12.008.

[10] S. Bhattacharyya, Energy access programmes and sustainable development: a critical review, Energy Sustain. Dev. 16 (2012) 260-271. http://dx.doi.org/ 10.1016/j.esd.2012.05.002.

[11] M.C. Haanyika, Rural electrification policy and institutional linkages, Energy Policy 34 (2006) 2977-2993. http://dx.doi.org/10.1016/j.enpol.2005.05.008.

[12] M. Bazilian, P. Nussbaumer, C. Eibs-Singer, A. Brew-Hammond, V. Modi, B. Sovacool, V. Ramana, P.K. Aqrawi, Improving access to modern energy services: insights from case studies, Electr. J. 25 (2012) 93-114. http://dx.doi.org/ 10.1016/j.tej.2012.01.007.

[13] M. Nouni, S. Mullick, T. Kandpal, Providing electricity access to remote areas in India: niche areas for decentralized electricity supply, Renew. Sustain Energy Rev. 34 (2008) 430-434. http://dx.doi.org/10.1016/j.renene.2008.05.006.

[14] S. Gangopadhyay, B. Ramaswami, W. Wadhwa, Reducing subsidies on household fuels in India: how will it affect the poor? Energy Policy 33 (2005) 2326-2336. http://dx.doi.org/10.1016/j.enpol.2004.04.024.

[15] R.K. Aggarwal, S.S. Chandel, Review of improved cookstoves programme in Western Himalayan State of India, Biomass Bioenergy 27 (2004) 131-144. http:// dx.doi.org/10.1016/j.biombioe.2004.01.001.

[16] W. Zhong Ying, G. Hu, Z. Dadi, China's achievements in expanding electricity access for the poor, Energy Sustain Dev. 10 (2006) 5-16. http://dx.doi.org/ 10.1016/S0973-0826(08)60539-6.

[17] O. Davidson, S. Mwakasonda, Electricity access for the poor: a study of South Africa and Zimbabwe, Energy Sustain Dev. 8 (2004) 26-40. http://dx.doi.org/ 10.1016/S0973-0826(08)60511-6.

[18] S. Karekezi, J. Kimani, Have power sector reforms increased access to electricity among the poor in East Africa? Energy Sustain Dev. 8 (2004) 10-25. http:// dx.doi.org/10.1016/S0973-0826(08)60510-4.

[19] M. Oseni, Household's access to electricity and energy consumption pattern in Nigeria, Renew. Sustain Energy Rev. (16) (2012) 990-995. http://dx.doi.org/ 10.1016/j.rser.2011.09.021.

[20] J. Goldemberg, L. La Rovere, T. Coelho, Expanding access to electricity in Brazil, Energy Sustain Dev. 8 (2004) 86-94. http://dx.doi.org/10.1016/S0973-0826(08) 60515-3.

[21] T. Slough, J. Urpelainen, J. Yang, Light for all? Evaluating Brazil's rural electrification progress, Energy Policy 86 (2015) 315-332. http://dx.doi.org/10.1016/ j.enpol.2015.07.001.

[22] Global Network on Energy for Sustainable Development, Energy Access Theme Results, Synthesis/Compilation Report, 2004 available at: http://www.gnesd.org/PUBLICATIONS/Energy-Access-Theme (Accessed 01.09.14).

[23] B.P. Bastakoti, Rural electrification and efforts to create enterprises for the effective use of power, Appl. Energy 76 (2003) 145-155. http://dx.doi.org/ 10.1016/S0306-2619(03)00055-2.

[24] Sn. Chakrabarti, Su. Chakrabarti, Rural electrification programme with solar energy in remote region - a case study in an island, Energy Policy 30 (2002) 33-42. http://dx.doi.org/10.1016/S0301-4215(01)00057-X.

[25] D.O. Akinyele, R.K. Rayudu, N.K.C. Nair, Development of photovoltaic power plant for remote residential applications: the socio-technical and economic perspectives, Appl. Energy 155 (2015) 131-149. http://dx.doi.org/10.1016/ j.apenergy.2015.05.091.

[26] T. Kobayakawa, C.T. Kandpal, Analysis of electricity consumption under a photovoltaic micro-grid system in India, Sol. Energy 116 (2015) 177-183. http:// dx.doi.org/10.1016/j.solener.2015.04.001.

[27] L. Ferrer-Marti, B. Domenech, A. Garcia-Villoria, R. Pastor, A MILP model to design hybrid wind-photovoltaic isolated rural electrification projects in developing countries, Eur. J. Operational Res. 226 (2013) 293-300. http://dx.doi.org/ 10.1016/j.ejor.2012.11.018.

[28] T. Levin, V.M. Thomas, Least-cost network evaluation of centralised and decentralised contributions to global electrification, Energy Policy 41 (2012) 286-302. http://dx.doi.org/10.1016/j.enpol.2011.10.048.

[29] M. Zeyringer, S. Pachauri, E. Schmid, J. Schmidt, E. Worrell, U. Morawetz, Analysing grid extension and stand-alone photovoltaic systems for the costeffective electrification on Kenya, Energy Sustain. Dev. 25 (2015) 75-86. http://dx.doi.org/10.1016/j.esd.2015.01.003.

[30] R. Banerjee, Comparison of options for distributed generation in India, Energy Policy 34 (2006) 101-111. http://dx.doi.org/10.1016/j.enpol.2004.06.006.

[31] I. Kessides, Powering Africa's sustainable development: the potential role of nuclear energy, Energy Policy 74 (2014) 557-570. http://dx.doi.org/10.1016/ j.enpol.2014.04.037.

[32] M.R. Nouni, S.C. Mullick, T.C. Kandpal, Biomass gasifier projects for decentralised power supply in India: a financial evaluation, Energy Policy 35 (2007) 1373-1385. http://dx. doi.org/10.1016/j.enpol.2006.03.016.

[33] H. Winkler, A. Simões, E. La Rovere, M. Alam, A. Rahman, S. Mwakasonda, Access and affordability of electricity in developing countries, World Dev. 39 (2011) 1037-1050. http://dx.doi.org/10.1016/j.worlddev.2010.02.021.

[34] A.L. Kooijman-van Dijk, J. Clancy, Impacts of electricity access to rural enterprises in Bolivia, Tanzania and Vietnam, Energy Sustain Dev. 14 (2010) 14-21. http://dx.doi.org/10.1016/j.esd.2009.12.004.

[35] E. Essah, Energy supply, consumption and access dynamics in Botswana, Sustain. Cities Soc. 12 (2014) 76-84. http://dx.doi.org/10.1016/j.scs.2014.01.006.
[36] N. Chouaibi, T. Abdessalem, Causality between electricity consumption and economic growth in Tunisia: policy implications, Int. J. Econ. Policy Emerg. Econ. 4 (2013) 211-226. http://dx.doi.org/10.1504/IJEPEE.2011.040915.

[37] I. Onyeji, M. Bazilian, P. Nussbaumer, Contextualizing electricity access in sub Saharan Africa, Energy Sustain. Dev. 16 (2012) 520-527. http://dx.doi.org/ 10.1016/j.esd.2012.08.007.

[38] N.M. Odhiambo, Electricity consumption and economic growth in South Africa: a trivariate causality test, Energy Econ. 5 (2009) 635-640. http://dx.doi.org/ 10.1016/j.eneco.2009.01.005.

[39] K. Zaman, M. Khan, M. Ahmad, R. Rustam, Determinants of electricity consumption function in Pakistan: old wine in an new bottle, Energy Policy 50 (2012) 623-634. http://dx.doi.org/10.1016/j.enpol.2012.08.003.

[40] A. Shiu, P. Lam, Electricity consumption and economic growth in China, Energy Policy 32 (2004) 47-54. http://dx.doi.org/10.1016/S0301-4215(02)00250-1.

[41] S. Pachauri, An analysis of cross-sectional variations in total households re quirements in India using micro survey data, Energy Policy 32 (2004) 1723-1735. http://dx.doi.org/10.1016/S0301-4215(03)00162-9.

[42] A. Kemmler, Factors influencing household access to electricity in India, Energy Sustain Dev. 11 (2007) 13-20. http://dx.doi.org/10.1016/S0973-0826(08)60405-6.

[43] O. Nanka-Bruce, The Socio Economic Drivers of Rural Electrification in Sub saharan Africa. Surrey Energy Economics Discussion Paper Series, Department of Economics, University of Surrey, 2010 available online at: http:// www.seec.surrey.ac.uk/research/SEEDS/SEEDS128.pdf.

[44] R. Loulou, U. Remme, A. Kanudia, A. Lehtila, Documentation of the TIMES Model, Energy Technology Systems Analysis Programme, 2005.

[45] M.I. Howells, T. Alfstad, D.G. Victor, G. Goldstein, U. Remme, A model of household energy services in a low-income rural African village, Energy Policy 33 (2005) 1833-1851. http://dx.doi.org/10.1016/j.enpol.2004.02.019.

[46] Study on Programme for Infrastructure Development in Africa (PIDA), Africa's Infrastructure Outlooks 2040, PIDA, 2010 available online at: http://www.foresightfordevelopment.org/sobipro/55/124-africas-infrastructure-outlooks-2040 (Accessed 11.09.13).

[47] M. Kanagawa, T. Nakata, Analysis of the energy access improvement and its socio-economic impacts in rural areas of developing countries, Ecol. Econ. 62 (2007) 319-329. http://dx.doi.org/10.1016/j.ecolecon.2006.06.005.

[48] M. Bazilian, P. Nussbaumer, H. Rogner, A. Brew-Hammond, V. Foster S. Pachuari, E. Williams, M. Howells, P. Niyongabo, L. Musaba, B. Gallachoir, M. Radka, D. Kammen, Energy access scenarios to 2030 for the power sector in Sub-Saharan Africa, Util. Policy 20 (2012) 1-16. http://dx.doi.org/10.1016/ j.jup.2011.11.002.

[49] S. Chakravarti, M. Tavoni, Energy poverty alleviation and climate change mitigation: is there a trade-off? Energy Econ. 40 (2013) S67-S73. http://dx.doi.org/ 10.1016/j.eneco.2013.09.022.

[50] T. Ekholm, V. Krey, S. Pachauri, K. Riahi, Determinants of household energy consumption in India, Energy Policy 38 (2010) 5696-5707. http://dx.doi.org/ 10.1016/j.enpol.2010.05.017.

[51] S. Messner, M. Strubegger, User's Guide for Message lii, Technical Report WP 95-69, International Institute for Applied Systems Analysis, 1995 available online at: http: / / www.iiasa.ac.at/publication/more_WP-95-069.php [Accessed 01.12.15].

[52] K. Narula, Y. Nagai, S. Pachauri, The role of decentralised distributed generation in achieving universal rural electrification in South Asia by 2030, Energy Policy 47 (2012) 345-357. http://dx.doi.org/10.1016/j.enpol.2012.04.075.

[53] S. Pachauri, N. Rao, Y. Nagai, K. Riahi, Access to Modern Energy: Assessment and Outlook for Developing and Emerging Regions, IIASA, 2012.

[54] S. Pachauri, B.J. Van Ruijven, Y. Nagai, K. Riahi, D.P. Van Vuuren, A. BrewHammond, N. Nakicenovic, Pathways to achieve universal household access to modern energy by 2030, Environ. Res. Lett. 8 (2013). http: / /dx.doi.org/10.1088/ $1748-9326 / 8 / 2 / 024015$

[55] GEA, Global Energy Assessment - toward a Sustainable Future, 2012. Cambridge University Press, Cambridge, UK and New York, NY, USA and the International Institute for Applied Systems Analysis, Laxenburg, Austria.

[56] International Energy Agency, World Energy Outlook - Methodology for Energy Access Analysis, WEO Model Documentation, 2012 available at: http:// www.worldenergyoutlook.org/weomodel/documentation/ (Accessed 20.05.15).

[57] B. Van Ruijeven, D.P. Van Vuuren, B. De Vries, M. Isaac, J. Van der Sluijs, P. Lucas, P. Balachandra, Model projections for household energy use in India, Energy Policy 39 (2011) 7747-7761. http://dx.doi.org/10.1016/ j.enpol.2011.09.021.

[58] J.M. De Vries, D.P. Van Vuuren, G.J.M. Den Elzen, A.M. Janssen, The Targets Image Energy Regional (TIMER) Model - Technical Documentation, RIVM Report 461502024 2001, November 2001

[59] B. Van Ruijven, J. Schers, D.P. Van Vuuren, Model-based scenarios for rural electrification in developing countries, Energy 38 (2012) 386-397. http:// dx.doi.org/10.1016/j.energy.2011.11.037.

[60] E. Panos, H. Turton, M. Densing, K. Volkart, Powering the growth of sub-Saharan africa: the jazz and symphony scenarios of world energy Council, Energy Sustain. Dev. 26 (2015) 14-33. http://dx.doi.org/10.1016/j.esd.2015.01.004.

[61] M. Densing, H. Turton, G. Bäuml, Conditions for the successful deployment of electric vehicles - a global energy system perspective, Energy 47 (2012) 137-149. http://dx.doi.org/10.1016/j.energy.2012.09.011.

[62] T. Gül, S. Kypreos, H. Turton, L. Barreto, An energy-economic scenario analysis of alternative fuels for personal transport using the global multi-regional MARKAL model (GMM), Energy 34 (2009) 423-437. http://dx.doi.org/10.1016/ j.energy.2009.04.010. 
[63] L. Barreto, Technological Learning in Energy Optimisation Models and the Deployment of Emerging Technologies, 2001. http://dx.doi.org/10.3929/ethz-a004215893. PhD No.14151, ETH Zürich, Switzerland.

[64] H. Turton, V. Panos, M. Densing, K. Volkart, Global Multi-regional MARKAL (GMM) Model Update: Disaggregation to 15 Regions and 2010 Recalibration, PSI Bericht 13-03, PSI, 2013. available at: http://www.psi.ch/eem/PublicationsTabelle/PSIBericht_13-03.pdf (Accessed 08.09.14).

[65] R. Loulou, G. Goldstein, K. Noble, Documentation for the MARKAL Family of Models, Energy Technology Systems Analysis Programme (ETSAP), 2004 available online at: http://www.iea-etsap.org/web/MrkLDoc-I_StdMARKAL.pdf (Accessed 22.11.13).

[66] International Monetary Fund (IMF), World Economic Outlook 2014, IMF, 2014. http://www.imf.org/external/pubs/ft/weo/2014/02/.

[67] World Bank, World Bank's Indicator Database, The World Bank Group, online at: http://data.worldbank.org/indicator/all (Accessed 13.02.15).

[68] International Energy Agency (IEA), World Energy Statistics and Balances, OECD/ IEA, http://dx.doi.org/10.1787/enestats-data-en.

[69] United Nations Population Division (UNPD), World Population Prospects: the 2012 Revision, UNPD, 2012 available online at: http://esa.un.org/wpp/index.htm (Accessed 11.02.15).

[70] G. Legros, I. Havet, N. Bruce, S. Bonjour, The Energy Access Situation in Developing Countries, World Health Organisation, United Nations Development Programme, 2009.

[71] D. Romer, Advanced Macroeconomics, fourth ed., McGraw-Hill, New York, 2012.

[72] G. Box, J. Gwilym, G. Reinsel, Time Series Analysis: Forecasting and Control, fourth ed., Wiley, 2008.

[73] J. Goldemberg, World Energy Assessment: Energy and the Challenge of Sustainability: Overview, UNDP, New York, 2000.

[74] A. Brew-Hammond, Energy access in africa: challenges ahead, Energy Policy 38 (2010) 2291-2301. http://dx.doi.org/10.1016/j.enpol.2009.12.016.

[75] P. Bocquier, World urbanization prospects: an alternative to UN model of projection compatible with the mobility transition theory, Demogr. Res. 12 (2005) 197-236. http://dx.doi.org/10.4054/DemRes.2005.12.9.

[76] W. Zelinsky, The Impasse in Migration Theory: a Sketch Map for Potential Escapees, Population Movements: Their Forms and Functions in Urbanization and Development, in: P.A. Morrison (Ed.), Ordina - IUSSP, Liege, 1983, pp. $19-46$.

[77] Hughes B., B., International Futures (IFs) modelling system, Version 7.08, Frederick S. Pardee Center for International Futures, Josef Korbel School of International Studies, University of Denver, http://www.ifs.du.edu/ifs/ frm_MainMenu.aspx (Accessed 20.02.15).

[78] Enel, Enabling Electricity: Right to Light, Electrification Programme for Latin America, 2012. http://www.enel.com/en-GB/sustainability/energy_access/ enabling_electricity/ (Accessed 20.02.15).

[79] Ministry of Mines and Energy Brazil, Programma Luz para Todos, 2003-2014. http://luzparatodos.mme.gov.br/luzparatodos/asp/ (Accessed 20.02.15).

[80] Indian Ministry of Power, Rural Electrification Programme, http://rggvy.gov.in/ rggvy/rggvyportal/index.html (Accessed 20.02.15).

[81] See for more details: http://www.powerdivision.gov.bd/user/brec/43/81 (Accessed 20.02.15).

[82] Nepal Electricity Authority, Community Rural Electrification Programme (CREP), http://www.nea.org.np/(Accessed 20.02.15).

[83] Department of Energy, Philippine Energy Plan, http://www.doe.gov.ph/policyand-planning/philippine-energy-plan (Accessed 20.02.15).

[84] Directorate General of Electricity, Rural Electrification in Indonesia: Target and Development, Country Report, 2012. http://energy-indonesia.com/03dge/ 05chiho.pdf (Accessed 20.02.15).

[85] Ministry of Industry and Trade, Vietnam National Development Strategy up to 2020 and Vision to 2050, Vietnam, 2011.

[86] Ministry of Energy \& Petroleum, National Electrification Schemes, http:// www.energymin.gov.gh/?page_id=181 (Accessed 20.02.15).

[87] Department of Energy, Integrated National Electrification Programme, http:// www.energy.gov.za/files/policies/p_electricity.html (Accessed 20.02.15).

[88] Rural Electrification Authority (REA), Rural Electrification Master Plan, http:// www.rea.org.zm/index.php/2013-08-24-13-50-58/remp (Accessed 20.02.15).
[89] T. Sanchez, The Hidden Energy Crisis: How Policies Are Falling the World's Poor, Practical Action Publishing, London, 2010.

[90] Government of India, Key Indicators of Household Consumer Expenditure in India 2009-10, Ministry of Statistics and Programme Implementation, New Delhi, 2011.

[91] V. Modi, S. McDade, D. Lallement, J. Saghir, Energy Services for the Millennium Development Goals, Energy Sector Management Assistance Programme, New York, 2006.

[92] R.G.V. Chandran, S. Sharma, K. Madhavan, Electricity consumption - growth nexus: the case of Malaysia, Energy Policy 38 (2010) 606-612. http://dx.doi.org/ 10.1016/j.enpol.2009.10.013.

[93] K.P. Narayan, R. Smyth, Multivariate granger causality between electricity consumption, exports and GDP: evidence from a panel of Middle Eastern countries,

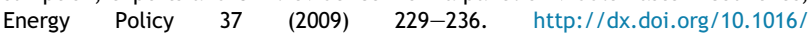
j.enpol.2008.08.020.

[94] K.P. Narayan, A. Prasad, Electricity consumption -real GDP causality nexus: evidence from a bootstrapped causality test for 30 OECD countries, Energy Policy 36 (2008) 910-918. http://dx.doi.org/10.1016/j.enpol.2007.10.017.

[95] J. Chontanawat, L. Hunt, L. Pierse, Causality between energy consumption and GDP: evidence from 30 OECD and 78 non-OECD countries, SEEDS 113 (2006). University of Surrey.

[96] N. Rao, Does, (better) electricity supply increase household enterprise income in India? Energy Policy 57 (2013) 532-541. http://dx.doi.org/10.1016/ j.enpol.2013.02.025.

[97] M. Grimm, R. Hartwig, J. Lay, Electricity access and the performance of micro and small enterprises: evidence from West Africa, Eur. J. Dev. Res. 25 (2013) 815-829. http://dx.doi.org/10.1057/ejdr.2013.16.

[98] A. Kooijman-van Dijk, The role of energy in creating opportunities for income generation in the Indian Himalayas, Energy Policy 41 (2012) 529-536. http:// dx.doi.org/10.1016/j.enpol.2011.11.013.

[99] United Nations Environment Programme, Financing Mechanisms and Public/Private Risk Sharing Instruments for Financing Small-scale Renewable Energy Equipment and Projects, UNEP, Paris, 2007.

[100] A. Yadoo, H. Cruickshank, The value of co-operatives in rural electrification, Energy Policy 38 (2010) 2941-2947. http://dx.doi.org/10.1016/ j.enpol.2010.01.031.

[101] E. Morris, S. Winiecki, S. Chowdhard, D. Cortiglia, Using Microfinance to Expand Access to Energy Services: Summary of Findings, Small Enterprise Education and Promotion Network (SEEP), 2007. Washington D.C.

[102] World Bank, Tanzania Energy Development \& Access Expansion, Procurement of Sustainable Solar Market Packages (SSMP), 2011, in: http: //www.worldbank.org/ projects/procurement/noticeoverview?id=OP00022900\&lang=en [Acessed 25.02.2015].

[103] World Bank, Lighting Africa: Catalyzing markets for modern off-grid lighting, http: //www.lightingafrica.org/.

[104] International Finance Corporation (IFC) and World Bank, Solar Lighting for the Base of the Pyramid - Overview of an Emerging Market, Lighting Africa Report, 2010. Washington D.C.

[105] World Bank, Africa Electrification Initiative Workshop, Conference Proceedings, Mozambique, Maputo, 2009.

[106] IPCC, Climate Change 2014: Mitigation of Climate Change. Contribution of Working Group III to the Fifth Assessment, Report of the Intergovernmental Panel on Climate Change, in: O. Edenhofer, R. Pichs-Madruga, Y. Sokona, E. Farahani, S. Kadner, K. Seyboth, A. Adler, I. Baum, S. Brunner, P. Eickemeier, B. Kriemann, J. Savolainen, S. Schlömer, C. von Stechow, T. Zwickel, J.C. Minx (Eds.), Cambridge University Press, Cambridge, United Kingdom and New York, NY, USA, 2014 available online at: http://www.ipcc.ch/report/ar5/wg3/ [Accessed 01.12.15].

[107] S. Pachauri, Household electricity access a trivial contributor to $\mathrm{CO}_{2}$ emissions growth in India, Nat. Clim. Change 4 (2014) 1073-1076. http://dx.doi.org/ 10.1038/nclimate2414.

[108] M. Bazilian, P. Nussbaumer, E. Haites, M. Levi, M. Howells, K. Yumkella, Understanding the scale of investment for universal electricity access, Geopolit. Energy 32 (2010) 21-42.

[109] Leopold A., Making Climate Change Mitigation More Meaningful: the Link to Universal Electricity Access, Rugby UK, Practical Action Publishing, doi: http:// dx.doi.org/10.3362/9781780448732. 